\title{
Convective-Permitting Hindcast Simulations during the North American Monsoon GPS Transect Experiment 2013: Establishing Baseline Model Performance without Data Assimilation
}

\author{
James M. Moker Jr., Christopher L. CAstro, and Avelino F. Arellano Jr. \\ Department of Hydrology and Atmospheric Sciences, The University of Arizona, Tucson, Arizona \\ YOLANDE L. SERRA \\ Joint Institute for Study of Atmosphere and Ocean, University of Washington, Seattle, Washington \\ DAVID K. ADAMS \\ Centro de Ciencias de la Atmósfera, Universidad Nacional Autónoma de México, Mexico City, Mexico
}

(Manuscript received 16 May 2017, in final form 14 April 2018)

\begin{abstract}
During the North American monsoon global positioning system (GPS) Transect Experiment 2013, daily convective-permitting WRF simulations are performed in northwestern Mexico and the southern Arizona border region using the operational Global Forecast System (GFS) and North American Mesoscale Forecast System (NAM) models as lateral boundary forcing and initial conditions. Compared to GPS precipitable water vapor (PWV), the WRF simulations display a consistent moist bias in the initial specification of PWV leading to convection beginning 3-6 h early. Given appreciable observed rainfall, days are classified as strongly and weakly forced based only on the presence of an inverted trough (IV); gulf surges did not noticeably impact the development of mesoscale convective systems (MCSs) and related convection in northwestern Mexico. Strongly forced days display higher modeled precipitation forecast skill than weakly forced days in the slopes of the northern Sierra Madre Occidental (SMO) away from the crest, especially toward the west where MCSs account for the greatest proportion of all monsoon-related precipitation. A case study spanning 8-10 July 2013 illustrates two consecutive days when nearly identical MCSs evolved over northern Sonora. Although a salient MCS is simulated on the strongly forced day (9-10 July 2013) when an IV is approaching the core monsoon region, a simulated MCS is basically nonexistent on the weakly forced day (8-9 July 2013) when the IV is farther away. The greater sensitivity to the initial specification of PWV in the weakly forced day suggests that assimilation of GPS-derived PWV for these types of days may be of greatest value in improving model precipitation forecasts.
\end{abstract}

\section{Introduction}

Severe thunderstorms are one of the principal natural hazards in the southwestern United States and adjacent northwestern Mexico, occurring predominantly from July to mid-September and especially during "burst" periods when organized convection is more favored (e.g., Carleton 1986; Douglas et al. 1993; Adams and Comrie 1997). Monsoon thunderstorms can cause damage and hazards from blowing dust from strong outflows, flash flooding from torrential rainfall,

Corresponding author: James M. Moker Jr., jmoker@email. arizona.edu and power outages from lightning strikes (McCollum et al. 1995; Gochis et al. 2007; Magirl et al. 2007; Griffiths et al. 2009). With respect to annual precipitation, convective precipitation related to the North American monsoon accounts for $60 \%-80 \%$ in northwestern Mexico and $40 \%$ in southwest United States (Douglas et al. 1993). The ability to quickly and accurately forecast the location and timing of monsoon thunderstorms is critical for the timely issuance of official watches and warnings in this binational region.

The accuracy of numerical weather prediction (NWP; acronyms used in this paper are listed in appendix B) forecasts during the monsoon depends on how well a given model forecast system can deterministically 
represent thunderstorm development and the key regional synoptic-scale features that facilitate convective organization. Thunderstorm development is strongly tied to the diurnal cycle of convection over complex terrain in both the southwestern United States (Raymond and Wilkening 1980; Damiani et al. 2008) and northwestern Mexico (Gochis et al. 2007; Lang et al. 2007; Nesbitt et al. 2008) with mesoscale convective systems (MCSs) being the dominant mechanism for severe weather (McCollum et al. 1995; Lang et al. 2007; Newman and Johnson 2012; Rowe et al. 2012). Precipitation from MCSs approaches the Gulf of California $(\mathrm{GoC})$ about $12 \mathrm{~h}$ later than the time of maximum diurnal convection in the SMO to the east (Johnson et al. 2007; Lang et al. 2007; Zuidema et al. 2007; Nesbitt et al. 2008). In the North American monsoon core region, defined as the region bounded by $24^{\circ}-30^{\circ} \mathrm{N}$ and $112^{\circ}-106^{\circ} \mathrm{W}$ (Higgins et al. 2006), MCSs account for the majority of the rainfall that falls west of the SMO (Castro et al. 2007; Newman and Johnson 2012).

A necessary condition for the development of monsoon convection is a favorable thermodynamic environment in terms of atmospheric instability and moisture (Johnson et al. 2007; Becker and Berbery 2008; Adams and Souza 2009). These criteria have been traditionally characterized by convective available potential energy (CAPE; Moncrieff and Miller 1976) and precipitable water vapor (PWV; Moore et al. 2015) metrics. However, during monsoon "burst" periods (Carleton 1986; Carleton et al. 1990; Adams and Souza 2009), transient uppertropospheric inverted troughs (IVs; Pytlak et al. 2005) facilitate convective organization, likely through both increasing instability and dynamical forcing (Douglas and Englehart 2007; Bieda et al. 2009; Finch and Johnson 2010). For example, Finch and Johnson (2010) argue that IVs modulate and intensify midlevel flow and shear leading to favorable conditions for convective organization in northwestern Mexico. From a climatological perspective, easterly vertical wind shear is also associated with one of the leading modes of monsoon precipitation (Seastrand et al. 2015). Climatologically, IVs are associated with an increase in organized propagating (MCS-like) convection in the North American monsoon core region (Bieda et al. 2009; Lahmers et al. 2016). Assessing exactly how the presence or absence of IVs impacts model forecast skill is a major objective of this study.

Surges of low-level tropical moisture (generally below $600 \mathrm{hPa}$ ) up the GoC (Douglas and Leal 2003; Rogers and Johnson 2007), hereinafter referred to as "gulf surges," are also important for the development of convection in the southwest United States (Hales 1972; Brenner 1974; Fuller and Stensrud 2000; Higgins et al. 2004), although our study brings into question their relevance for low-level moisture south of this region in northwest Mexico. "Major" gulf surges are often triggered by the passage of a low-pressure disturbance near the mouth of the gulf such as a tropical cyclone (TC) or tropical easterly wave (TEW; Fuller and Stensrud 2000; Douglas and Leal 2003; Higgins and Shi 2005), and traverse the entire length of the gulf over a period of several days (Zehnder 2004; Serra et al. 2016). TCs can also make direct landfall into northwest Mexico and the southwest United States, although this typically occurs in October at the end of the monsoon season (Wood and Ritchie 2013). "Minor" gulf surges triggered by the convective outflow boundaries of decaying MCSs can last several hours and are confined to the northern GoC (Hales 1972; Fuller and Stensrud 2000; Lang et al. 2007). IVs can also be an indirect cause of minor gulf surges in their support of MCS development (Douglas and Leal 2003; Lang et al. 2007).

Operational forecast models typically resolve features at the meso- $\alpha$ scale $(100-1000 \mathrm{~km})$ therefore representing features important to the monsoon like the longwave atmospheric circulation pattern over western North America during the warm season (e.g., monsoon ridge positioning) and transient synoptic features (e.g., IVs). However, to explicitly represent storm-scale structures like squall lines and outflow boundaries (e.g., Li et al. 2008), the use of convective-permitting atmospheric modeling at the meso- $\gamma$ scale (i.e., model grid spacing on the order of $1-4 \mathrm{~km}$ without cumulus parameterization) is necessary. Since MCSs are dependent upon antecedent meso- $\gamma$-scale features, they cannot be resolved by large-domain operational forecast models that focus on the meso- $\alpha$ scale and larger (Gutzler et al. 2009).

The North American Monsoon Experiment (NAME; Higgins et al. 2006) in 2004 advanced our knowledge of convective processes in the North American monsoon core region (see Higgins and Gochis 2007) and provided a valuable dataset for assessing model representation of monsoon convection. However, a noted major weakness in the NAME observational network experimental design was the lack of measurements of both the diurnal cycle of the boundary layer and moisture fluxes at higher elevations away from the coast (Higgins and Gochis 2007), a critical region for monsoon convective initiation. This lack of measurements strongly motivated the North American Monsoon GPS Transect Experiment 2013 (Transect 2013) (Adams et al. 2014; Serra et al. 2016) that included 10 GPS meteorological stations that were installed in northwest Mexico to capture the evolution of PWV during convection initiation through organization and propagation from the highest elevations of the SMO to the coastal plains of the GoC.

In our study, we use a convective-permitting model to downscale operational forecasts over northwest Mexico 
during Transect 2013. Using a similar model, Kursinski et al. (2008a) showed that a 5\% change in initial PWV values (within the analysis error) significantly changes the amount of convective precipitation over northwestern Mexico, therefore implying that monsoon convective forecasts are sensitive to the initial specification of PWV. Here, we report on the results of validating our forecasts against satellite rainfall and surface observations from the Transect 2013 dataset. A follow-on study will document the results of the assimilation of GPS PWV into the model forecasts.

\section{Data and model description}

\section{a. GPS PWV from the Transect 2013 experiment}

In the previous section, we introduced Transect 2013 where 10 GPS meteorological sensors were deployed across northwest Mexico within the North American monsoon core region during summer 2013. These GPS sensors are indicated by black dots in the bottom panel of Fig. 1 and were set up into three strategically placed transects (Serra et al. 2016) whose configuration and monitoring purposes are summarized in Table 1. The longer-term SuomiNet GPS stations (http://www.suominet.ucar.edu), principally located within the United States at the time of this study, are indicated by triangles the bottom panel of Fig. 1. Gulf surges identified by the coastal transect have the advantage of being based on full-tropospheric moisture and are consequently less subject to localized land surface effects (e.g., surface dewpoint). Additionally, the advection of moisture along the gulf can be monitored to estimate the speed and extent of the surge, which, as discussed above, has important consequences for the location of convective outbreaks mainly in the southwest United States. The SMO transect, whose terrain cross section is highlighted in Fig. 2, offers a first-time look at in situ high-frequency PWV evolution during convective initiation in the higher elevations and thereby filling the gap in the NAME dataset in this locale that was noted by Higgins and Gochis (2007).

GPS meteorological sensors also provide standard meteorological variables including precipitation at 1-min temporal resolution. GPS PWV is high frequency $(\sim 5 \mathrm{~min})$ and all weather, which makes it particularly advantageous for rapidly evolving cloudy and rainy conditions. For example, the strong upswing in PWV prior to deep convective events in association with water vapor convergence (Kursinski et al. 2008a,b; Adams et al. 2011, 2013, 2015) permits the use of the time rate of change of PWV for identifying the events as well as a proxy for their intensity. Global Navigation and Satellite Systems (GNSS)-Inferred Positioning
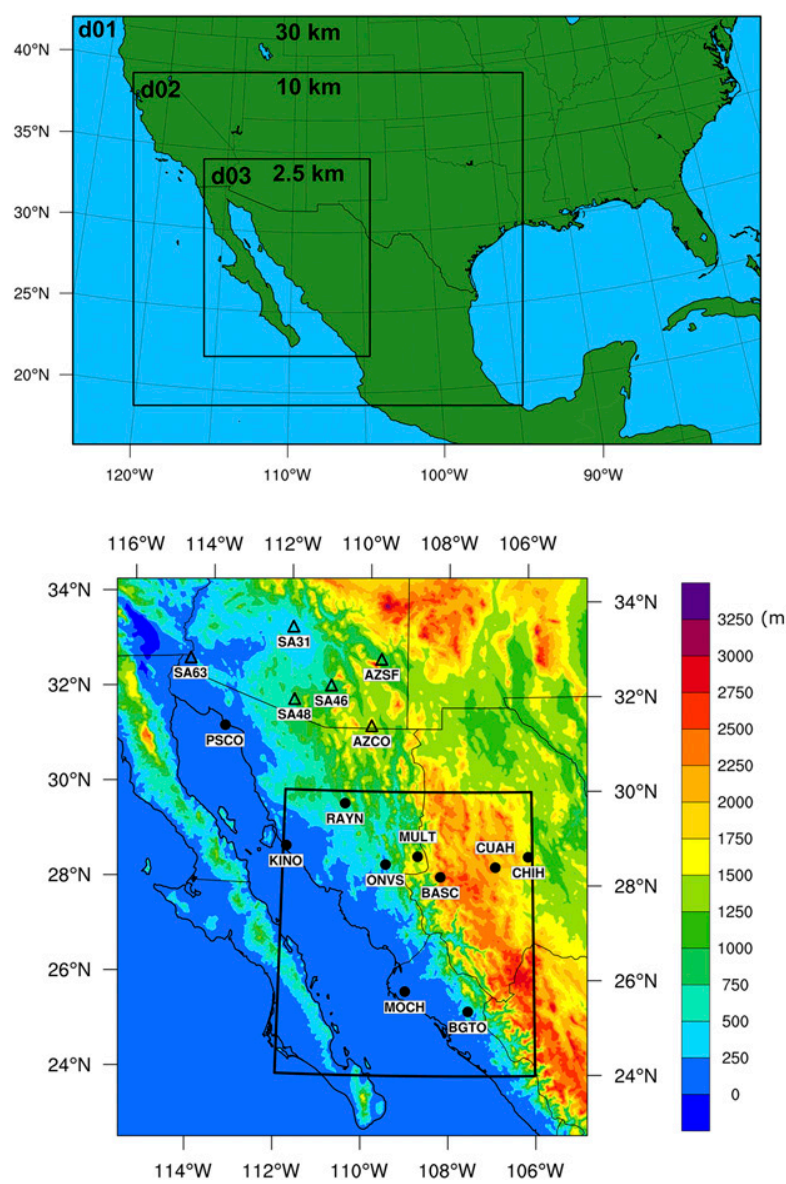

FIG. 1. (top) The WRF-ARW nested domain configuration in our hindcast setup. Domain d01 has 159 (west-east) $\times 99$ (south-north) grid points with a horizontal spacing of $30 \mathrm{~km}$, domain $\mathrm{d} 02$ has $270 \times 231$ grid points with a horizontal spacing of $10 \mathrm{~km}$, and the innermost domain $\mathrm{d} 03$ has a $460 \times 548$ grid points with a horizontal spacing of $2.5 \mathrm{~km}$. (bottom) Domain d03 with locations of the Transect 2013 (circles) and SuomiNet (triangles) stations as well as terrain shaded every $250 \mathrm{~m}$. The SMO transect (KINO-CHIH) is situated within the northern third of the North American monsoon core region outlined in black and bounded by $24^{\circ}-30^{\circ} \mathrm{N}$ and $112^{\circ}-106^{\circ} \mathrm{W}$.

System and Orbit Analysis Simulation Software (GIPSYOASIS; https://gipsy-oasis.jpl.nasa.gov/) is used to obtain PWV from the GPS signal at 5-min temporal resolution. For more information on the derivation of PWV from the GPS signal, see Bevis et al. (1992). One of the 10 stations, RAYN, failed in mid-July and was excluded from the analysis.

\section{b. Gridded precipitation dataset}

The gridded rainfall dataset that we use for verification purposes in our northwest Mexico domain is the Tropical Rainfall Measuring Mission (TRMM) Multisatellite Precipitation Analysis (TMPA) 3B42, version 7, dataset (referred to hereinafter as TRMM; 
TABLE 1. List of station names, locations, and elevations for each station in each transect within Transect 2013 along with its purpose.

\begin{tabular}{llllcl}
\hline \hline SMO transect & Station & Lat $\left({ }^{\circ} \mathrm{N}\right)$ & Lon $\left({ }^{\circ} \mathrm{W}\right)$ & Elev $(\mathrm{m} \mathrm{MSL})$ & Purpose \\
\hline SMO transect & KINO & 28.8149 & 111.9287 & 7 & To observe the development of MCSs in the core \\
& ONVS & 28.4602 & 109.5288 & 189 & region at high temporal resolution from convec- \\
& MULT & 28.6356 & 108.7595 & 1550 & tive initiation at the northern SMO crest (BASC- \\
& BASC & 28.2035 & 108.2098 & 1999 & CUAH) to organization and propagation along \\
& CUAH & 28.4079 & 106.8922 & 2058 & the western SMO slope/foothills \\
Coastal transect & CHIH & 28.6224 & 106.1006 & 1463 & (MULT-ONVS) and toward the GoC (KINO) \\
& MOCH & 25.7815 & 109.0264 & 15 & To observe the propagation of gulf surges along the \\
& KINO & 28.8149 & 111.9287 & 7 & GoC from south to north (MOCH-KINO-PSCO) \\
Southern transect & PSCO & 31.3004 & 113.5483 & 53 & To observe the strong precipitation gradient be- \\
& MOCH & 25.7815 & 109.0264 & 15 & tween the central GoC (MOCH) and the central \\
& BGTO & 25.3625 & 107.5511 & 207 & SMO foothills (BGTO)
\end{tabular}

Huffman et al. 2007) based on its past performance that compared it three other datasets with similar subdaily temporal resolutions capable of resolving the diurnal cycle of convective precipitation: Precipitation Estimation from Remotely Sensed Information Using Artificial Neural Networks (PERSIANN; Sorooshian et al. 2000), Global Satellite Mapping of Precipitation (GSMaP; Okamoto et al. 2005; Kubota et al. 2007; Aonashi et al. 2009; Ushio et al. 2009), and the Climate Prediction Center (CPC) morphing technique (CMORPH; Joyce et al. 2004) datasets. These datasets have unique ways of incorporating infrared geostationary satellite data, polar-orbiting satellite microwave data, and/or gauge observations, as well as additional analysis methods to determine quantitative precipitation estimates (QPE) that are explained in detail in their respective references in Table 2. Stage IV is a combined WSR-88D radar and gauge-based gridded rainfall product within the United States that Chen et al. (2015) consider the "benchmark for validating other radar- or satellite-based QPE products" (p. 4445). They show that Stage IV and TRMM display similar spatial precipitation patterns over the United States and state that their results "cast a vote of confidence for the satellite QPE algorithm" of TRMM to be a reference for developers of a QPE algorithm in the Global Precipitation Measurement (GPM). Stillman et al. (2016) examine TRMM, CMORPH, and PERSIANN satellite precipitation datasets across the Walnut Gulch Experimental Watershed (WGEW), a $150 \mathrm{~km}^{2}$ desert watershed in southeast Arizona just to the north of the SMO, and find that TRMM performs the best and PERSIANN the worst when compared to observations during the warm season. Tian et al. (2010) compared TRMM, GSMaP, CMORPH, and PERSIANN. In the western United States, in contrast to TRMM, they show that GSMaP, CMORPH, and PERSIANN generally miss the heaviest rain rates (greater than $40 \mathrm{~mm} \mathrm{day}^{-1}$ ) and overestimate precipitation, particularly in the warm season.

\section{c. Other observational and atmospheric reanalysis data sources}

Data sources used to identify synoptic features such as IVs, TEWs, and tropical cyclones (TCs) as well as to calculate gulf surges outside of the coastal transect are described in Table 3.

\section{d. WRF-ARW Model configuration and hindcast simulations}

The Advanced Research version of the Weather Research and Forecasting (WRF-ARW; Skamarock et al. 2008) Model, version 3.41, is used for retrospective daily convective simulations (referred to as hindcasts) for the duration of Transect 2013. The WRF-ARW configuration is based on the real-time quasi-operational model at the University of Arizona within the Department of Hydrology and Atmospheric Sciences (UA HAS), hereinafter referred to as UA-WRF (http://www.atmo.arizona. edu/?section $=$ weather\&id $=$ wrf), whose configuration was also the basis for a study that dynamically downscaled

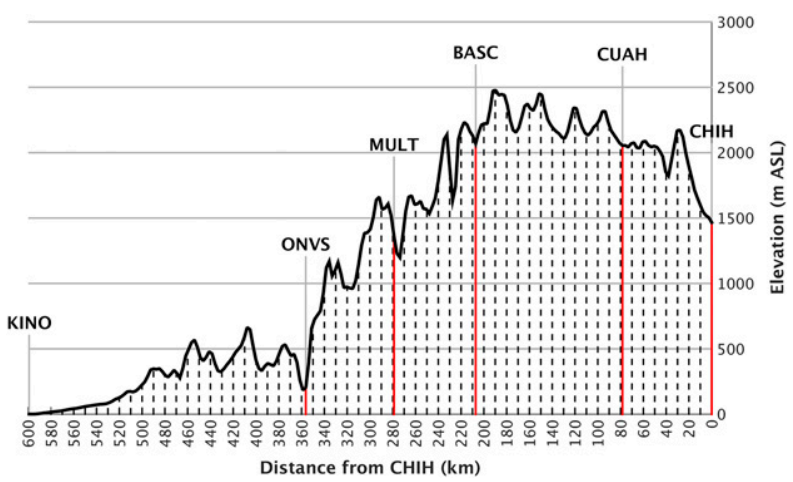

FIG. 2. A west-to-east cross section of the mountainous terrain (m MSL) shows the locations of the SMO transect stations indicated by red solid vertical lines. Distance relative to the easternmost station $\mathrm{CHIH}$ is indicated by black dashed lines along the abscissa. 
TABLE 2. Satellite-based precipitation datasets available during the period of study.

\begin{tabular}{|c|c|c|c|c|}
\hline Product & Source & $\begin{array}{c}\text { Time } \\
\text { resolution }\end{array}$ & $\begin{array}{l}\text { Spatial } \\
\text { resolution }\end{array}$ & References \\
\hline CMORPH & NOAA & 3-hourly & $0.25^{\circ}$ & Joyce et al. (2004) \\
\hline GSMap & JAXA & Hourly & $0.10^{\circ}$ & $\begin{array}{l}\text { Okamoto et al. } \\
(2005) \\
\text { Kubota et al. (2007) } \\
\text { Aonashi et al. (2009) } \\
\text { Ushio et al. (2009) }\end{array}$ \\
\hline PERSIANN & UCI & 3-hourly & $0.25^{\circ}$ & $\begin{array}{l}\text { Sorooshian et al. } \\
\quad(2000)\end{array}$ \\
\hline TRMM & NASA & 3-hourly & $0.25^{\circ}$ & Huffman et al. (2007) \\
\hline
\end{tabular}

regional climate models (Luong et al. 2017). Our model uses three nested domains ( $\mathrm{d} 01, \mathrm{~d} 02$, and $\mathrm{d} 03$ ), as described in Table 4, that feature 27 vertical levels with a terrain-following hydrostatic pressure coordinate that is a traditional sigma coordinate (Skamarock et al. 2005). The innermost domain (d03) closely corresponds to the NAME Tier I region (which itself encompasses the monsoon core region) and since it has a $2.5-\mathrm{km}$ horizontal grid spacing, it explicitly resolves convection at the meso- $\gamma$ scale. The coarser domains of d01 and d02 (30- and 10-km horizontal grid spacing, respectively) employ the Kain-Fritsch cumulus parameterization scheme (Kain 2004). Other model physics applied to all domains is shown in Table 5.

The hindcasts are executed daily during the Transect 2013 period for 79 days (from 26 June through 12 September 2013) in two sets of simulations that have different initial conditions and 6-hourly lateral boundary conditions: 1$)$ the NAM model $(32-\mathrm{km}$ horizontal grid spacing) and 2) GFS model $\left(0.25^{\circ}\right.$ horizontal grid spacing). To capture the diurnal cycle of convection, the hindcasts are initialized at 1200 UTC (0500 LT) and run for $24 \mathrm{~h}$. The Rapid Refresh (RAP) model is used to initialize the soil moisture and temperature because these surface data have finer spatial resolution as compared to the NAM and GFS models.

\section{Analysis methods}

\section{a. Assessment of synoptic features}

Following Douglas and Englehart (2007), who summarized transient features of the 2004 monsoon season in NAME, we track IVs, gulf surges, TEWs, and tropical cyclones (TCs) during the Transect 2013 period. These features are then used to categorize days by the synoptic forcing conditions to assess their relative impact on forecast skill within the hindcasts.

\section{1) IDENTIFICATION OF TRANSIENT SYNOPTIC FEATURES}

We subjectively determine an IV, based on Bieda et al. (2009), by an area of enhanced relative vorticity that moves westward along the southern periphery of the monsoon high and is depicted by a swirl pattern in the GOES water vapor infrared channel. Additionally, North American Regional Reanalysis (NARR)-A 300-hPa geopotential height and wind fields are also examined to confirm the IV presence. We note IVs that approach the NAME Tier I region (monsoon core).

We objectively identify TEWs from the ERA-Interim reanalysis and GFS analysis using a vorticity-tracking algorithm (Hodges 1994, 1995) that was previously shown to be effective in tracking TEWs across the tropical Atlantic and east Pacific (e.g., Thorncroft and Hodges 2001; Serra et al. 2010). We identify a TEW as a vertically averaged relative vorticity feature over the

TABLE 3. Descriptions of other observational and atmospheric reanalysis datasets used in this study.

\begin{tabular}{|c|c|c|}
\hline Dataset & Source & Purpose \\
\hline $\begin{array}{l}\text { Surface meteorological data from Naval Air } \\
\text { Station Yuma (KNYL) }\end{array}$ & Mesowest (http://mesowest.utah.edu) & $\begin{array}{l}\text { To calculate a gulf surge in addi- } \\
\text { tion to the coastal transect }\end{array}$ \\
\hline $0.25^{\circ} 3$-hourly TMPA (Huffman et al. 2007) & $\begin{array}{l}\text { NASA's Goddard Earth Sciences Data } \\
\text { and Information Services Center } \\
\text { (https://mirador.gsfc.nasa.gov/) }\end{array}$ & $\begin{array}{l}\text { Observed precipitation to compare } \\
\text { with hindcasts }\end{array}$ \\
\hline $\begin{array}{l}\text { NOAA's 4-km GOES-East satellite imag- } \\
\text { ery (water vapor IR channel) }\end{array}$ & $\begin{array}{l}\text { Iowa Environmental Mesonet (http:// } \\
\text { mesonet.agron.iastate.edu/archive/data) }\end{array}$ & To subjectively depict IVs \\
\hline $\begin{array}{l}\text { NARR dataset ( } 29 \text { vertical levels, 32-km } \\
\text { horizontal resolution, 3-h temporal } \\
\text { resolution) (Mesinger et al. 2006) }\end{array}$ & $\begin{array}{l}\text { NOAA Operational Model Archive and } \\
\text { Distribution System (NOMADS) (https:// } \\
\text { nomads.ncdc.noaa.gov/data/narr/) }\end{array}$ & A secondary tool to visualize IVs \\
\hline $\begin{array}{l}\text { ERA-Interim dataset ( } 60 \text { vertical levels, } \\
\sim 70 \text {-km horizontal resolution, } 3 \text {-h tem- } \\
\text { poral resolution) (Dee et al. } 2011 \text { ) }\end{array}$ & $\begin{array}{l}\text { ECMWF public datasets (http://apps. } \\
\text { ecmwf.int/datasets) }\end{array}$ & To track TEWs \\
\hline $\begin{array}{l}\text { "Past track seasonal maps" in the Eastern } \\
\text { Pacific for } 2013 \text { based on the HURDAT } \\
\text { "best track" database }\end{array}$ & $\begin{array}{l}\text { NOAA's National Hurricane Center } \\
\text { (http://www.nhc.noaa.gov/data) }\end{array}$ & To identify TCs \\
\hline
\end{tabular}


TABLE 4. Horizontal resolutions of the 3 nested WRF-ARW domains along with the cumulus parameterization scheme, if used.

\begin{tabular}{lccc}
\hline \hline & $\mathrm{d} 01$ & $\mathrm{~d} 02$ & $\mathrm{~d} 03$ \\
\hline Horizontal resolution & $30 \mathrm{~km}$ & $10 \mathrm{~km}$ & $2.5 \mathrm{~km}$ \\
Cumulus parameterization & Kain-Fritsch & Kain-Fritsch & None \\
\hline
\end{tabular}

850-600-hPa layer that exceeds $+5 \times 10^{-6} \mathrm{~s}^{-1}$ with the following requirements: 1 ) the vorticity feature persists for at least 2 days, 2) its track has a length of at least $1000 \mathrm{~km}$, and 3) its track passes within $500 \mathrm{~km}$ of the mouth of the GoC. Similar TEW tracks were found in the ERA-Interim and GFS vorticity fields (not shown). If a TEW track coincided with a TC identified in the "best track" database, then that track is categorized as a TC (not a TEW). Note: Two TEWs that occurred were not initially found by the objective vorticity tracking algorithm and were not included. They were later verified by both GOES infrared imagery and NWS area forecast discussions.

Gulf surges are identified using hourly Transect 2013 GPS PWV at the three coastal transect stations (MOCH, KINO, and PSCO) and hourly dewpoint temperature at Yuma, Arizona (KNYL), located north of the GoC. In the coastal transect, per Serra et al. (2016), we first calculate a 24-h moving average of PWV to smooth the data. Then, we calculate a percent increase from the minimum PWV in a previous 24 - $\mathrm{h}$ period to the maximum PWV in the current 24-h period (ending at 1200 UTC to match the hindcasts). The thresholds used to identify a gulf surge are specific to each of the three GoC sites and are based on the minimum PWV percent increase for each site out of all three gulf surges in Fig. 4 of Serra et al. (2016): $11 \%$ at MOCH, $19 \%$ at KINO, and $28 \%$ at PSCO. North of the GoC, after smoothing hourly dewpoint temperatures at KNYL via a 24-h moving average, we identify gulf surges with two criteria: 1) a minimum dewpoint increase of $4^{\circ} \mathrm{C}$ in 2 consecutive 24 -h periods that is based on the three gulf surges in Fig. 4 of Serra et al. (2016), and 2) a dewpoint temperature of at least $18^{\circ} \mathrm{C}\left(\sim 64^{\circ} \mathrm{F}\right)$ in the current 24-h period that is partially based on the NWS method that uses this daily mean dewpoint temperature as one of its two threshold criteria (NWS Tucson 2015, personal communication).

\section{2) CRITERIA FOR IDENTIFYING STRONGLY AND WEAKLY FORCED DAYS}

As a first pass, we classify days as strongly or weakly forced based on the presence of one or more of the synoptic features discussed in the previous section known from the literature to facilitate convective organization in the North American monsoon region based on
TABLE 5. Listing of the physics schemes that are used in our WRFARW configuration and applied to all domains.

\begin{tabular}{|c|c|c|}
\hline Category & Scheme & Reference \\
\hline Microphysics & $\begin{array}{l}\text { WRF single-moment } \\
\text { 6-class }\end{array}$ & Hong and Lim (2006) \\
\hline $\begin{array}{l}\text { Planetary } \\
\text { boundary layer }\end{array}$ & Yonsei University & Hong et al. (2006) \\
\hline $\begin{array}{l}\text { Longwave } \\
\text { radiation }\end{array}$ & $\begin{array}{l}\text { Rapid Radiative } \\
\text { Transfer Model }\end{array}$ & Iacono et al. (2008) \\
\hline $\begin{array}{l}\text { Shortwave } \\
\text { radiation }\end{array}$ & Goddard & $\begin{array}{l}\text { Chou and Suarez (1999); } \\
\text { Chou et al. (2001) }\end{array}$ \\
\hline $\begin{array}{l}\text { Land surface } \\
\text { model }\end{array}$ & Unified Noah & Tewari et al. (2004) \\
\hline
\end{tabular}

Douglas and Englehart (2007). We choose days when organized convection propagates off the high terrain of the SMO toward the west over the lower elevations of Sonora and the border region of southern Arizona, as documented in the 2013 Monsoon Weather Discussions led by UA HAS graduate students and part of the Transect 2013 field campaign (https://monsoonwx2013. wordpress.com). To disregard days with monsoon breaks and light convective activity, we use TRMM to identify days when precipitation fell along the northern SMO crest and to the north and west toward the lower elevations of northwest Mexico and adjacent extreme southern Arizona. Only days with 24-h accumulations of at least $20 \mathrm{~mm}$ in at least five grid points in a region bounded by $26.0^{\circ}-32.5^{\circ} \mathrm{N}$ and $114^{\circ}-107.25^{\circ} \mathrm{W}$ (except for the $\mathrm{GoC}$ and Baja Peninsula) are considered.

\section{b. Statistical performance metrics for WRF Model simulations}

Given the sensitivity of model rainfall to initial specification of PWV found by Kursinski et al. (2008a), we compare model PWV for the sets of strongly and weakly forced days to observed GPS PWV. These results are then used to interpret analysis of hindcast rainfall against TRMM observations.

\section{1) Evaluation of MOdeled PWV}

For direct comparisons of GPS-derived PWV and WRF-simulated PWV, the time and location are first matched with instantaneous PWV values extracted directly from the Transect 2013 and SuomiNet GPS datasets every third hour (i.e., 1200, 1500, 1800, ..., 1200 UTC). Then, the WRF-simulated PWV is mapped to each GPS site using vertical integration and inverse-distance squared weighting schemes that are described in appendix A. Mean bias and root-mean-square error (RMSE) are computed between GPS observations and WRF-simulated (model) values. Here, mean bias is defined as the model mean 
TABLE 6 . A $2 \times 2$ forecast contingency table as input for the CSI, POD, and FAR metrics to calculate precipitation forecast skill for each grid point.

\begin{tabular}{llll}
\hline \hline & & \multicolumn{2}{c}{ Observed? } \\
\cline { 3 - 4 } & & \multicolumn{1}{c}{ Yes } & \multicolumn{1}{c}{ No } \\
\hline Forecast? & Yes & $A$ (hits) & $B$ (false alarms) \\
& No & $C$ (misses) & $D$ (correct negatives) \\
\hline
\end{tabular}

minus the observation mean. In this convention, a negative (positive) mean bias indicates a dry (moist) model bias relative to the observations. RMSE is defined as the square root of the mean squared differences between the observed and modeled values (Wilks 1995). A paired observation-model two-tailed $t$ test is used to determine the level of statistical significance of the differences of the mean biases.

\section{2) EVALUATION OF MODELED RAINFALL}

To compare TRMM precipitation with the d03 WRF modeled precipitation, the 3-h TRMM mean precipitation rate is first converted to 3-h accumulations to match the time interval of the output of the WRF hindcasts. Then, WRF precipitation is scaled up from its $2.5-\mathrm{km}$ horizontal resolution to $0.25^{\circ}$ to match that of TRMM using the Earth System Modeling Framework (ESMF) "conserve" function within NCL. For each 3-h forecast period, modeled precipitation (WRF) is subtracted from observed precipitation (TRMM) to produce the bias maps for the combination of both strongly and weakly forced days.

Precipitation forecast skill is evaluated by first completing a $2 \times 2$ forecast contingency matrix (Table 6 ) and then calculating the critical success index (CSI; Donaldson et al. 1975), probability of detection (POD), and false-alarm ratio (FAR) at each grid point for a subset of days. Mason (1989) and Schaefer (1990) have shown that CSI is a biased metric that is dependent on the number of observed events. To address this bias, POD and FAR were added to the analysis. The metrics range from 0 to 1 . CSI and POD have a perfect (zero) forecast skill of $1(0)$. FAR has a perfect (zero) forecast skill of 0 (1). CSI is defined as a ratio of hits $(A)$ to observed events $(A+C)$ and false alarms $(B)$ :

$$
\mathrm{CSI}=\frac{A}{(A+B+C)} .
$$

POD is defined as the ratio of hits $(A)$ to observed events $(A+C)$ :

$$
\mathrm{POD}=\frac{A}{(A+C)}
$$

FAR is defined as the ratio of false alarms $(B)$ to total forecasts $(A+B)$ :

$$
\mathrm{FAR}=\frac{B}{(A+B)} .
$$

We define a precipitation event at a grid point that has at least $2.5 \mathrm{~mm}(10 \mathrm{~mm})$ of accumulation in the 6-h (daily) periods and at least 3 observed events in both the strongly and weakly forced days subsets. We use a neighborhood verification technique that considers modeled events in \pm 2 grid points where each grid point is assigned a weighted average of the difference of the metric between the strongly and weakly forced subsets of days. The metric is undefined for a grid point if any of the subsets have 1) less than 3 observed events or 2) no modeled events in all neighborhood grid points. For each grid point, a two-tailed statistical local significance test ( $p$ value $<0.10$ ) was established via 1000 permutations in a Monte Carlo resampling method. Only grid points that containing at least 900 unique values are used. Finally, the statistical field significance is obtained in a method similar to Livezey and Chen (1983) using the same permutation method as a local test but with the resampling of the maps. The 900th value $(90 \%)$ of the histogram is the critical value for statistical field significance. Pattern correlations are computed between the common grid points of the subdaily maps and daily maps.

\section{3) FORWARD MODEL SENSITIVITY EXPERIMENTS}

To demonstrate the potential impact of constraining the moisture fields in WRF, we conduct a suite of analyses on the forward sensitivity of WRF PWV and rainfall to the initial specification of PWV at GPS transect sites that is described in appendix A.

\section{Model performance for strong and weak days}

\section{a. Overview of 2013 NAM season}

Synoptic forcing mechanisms affecting convective precipitation coinciding with the Transect 2013 period are shown in Fig. 3. IVs were the most prevalent features with 28 days impacted by 12 events. This was followed by 26 days being impacted by 6 TCs. Two TEW tracks (impacting 4 days) that came within $500 \mathrm{~km}$ of the mouth of the GoC were not associated with TCs. The remaining TEWs were actually TCs, or in one instance developed into a TC, and thus were not included in the TEW count (Fig. 3). The tropical activity in the eastern North Pacific in 2013 was above average with 18 TCs occurring versus a seasonal average of 15 for this basin from 1971 to 2009 (http://www.nhc.noaa.gov/, accessed 2 December 2016). 


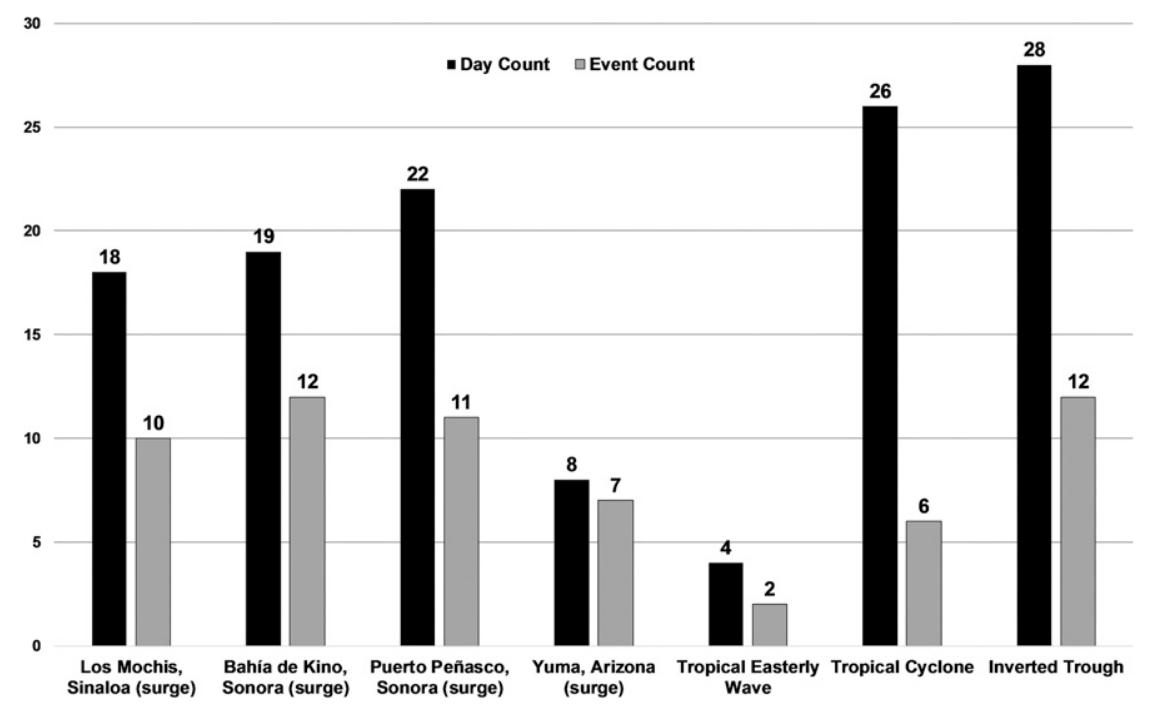

FIG. 3. Counts of synoptic forcing mechanisms during the 2013 season (27 Jun-9 Sep) that have been demonstrated to impact North American monsoon convection in northwest Mexico and adjacent southwest United States. The first four cities indicate sites recording gulf surges. The event count (gray) shows the actual number of forcing mechanisms, while the day count (black) is the number of days that were affected by that particular forcing mechanism.

No TCs directly impacted the land areas in northwest Mexico and adjacent southwest United States.

Sixteen gulf surges were identified in the coastal transect and KNYL with 5 surges initiated by TCs. One TEW initiated an additional gulf surge. Gulf surges were identified at MOCH (10), KINO (12), PSCO (11), and KNYL (7). In the coastal transect, an adjacent upstream station that recorded a gulf surge on the same or following day was considered part of the same event. Because surface dewpoint temperature data could lag or lead a PWV signal, we allowed gulf surges identified at KNYL an error of \pm 1 day to be considered part of the same event. Adams and Comrie (1997) differentiated between "major" and "minor" surges where "major" surges initiate near the GoC mouth and traverse the entire GoC while "minor" surges initiate partway up the GoC from cool MCS outflow and run the balance of the GoC. Out of the 16 total gulf surges, 7 were "major" in that they were observed at all 3 coastal transect sites (MOCH, KINO, and PSCO) and 4 of these also being observed at KNYL. Five of the gulf surges were "minor" if they were observed at PSCO or KNYL, but did not include all coastal transect sites. A third category of "partial" was defined for 4 gulf surges that did not reach PSCO.

Considering only days when appreciable rainfall was observed in northwest Mexico and adjacent southwest United States (i.e., monsoon active periods), we identify 22 strongly forced and 41 weakly forced days (Table 7). Since no consistent relationship is observed between the presence or absence of a gulf surge and a strongly forced or weakly forced day, we conclude that a strongly forced day solely requires the presence of an IV and, conversely, a weakly forced day requires the absence of an IV. The lack of a strong relationship between gulf surges and day classification suggests that MCSs initiating in northwest Mexico are not dependent upon gulf surges for their development. This is in contrast to convection that occurs in Arizona where gulf surges play a more integral role as indicated by previous literature (e.g., Hales 1972; Brenner 1974; Fuller and Stensrud 2000; Higgins et al. 2004). Comparing the mean upper-tropospheric winds at $300 \mathrm{hPa}$ from NARR data suggests that enhanced easterly winds, and thus higher vertical wind shear, were present over the northern SMO on the strongly forced days than on weakly forced days (not shown). We hypothesize that the hindcasts will exhibit better performance of representing observed precipitation for the strongly forced days because an IV would be present within the convective-permitting domain of the WRF simulations (core monsoon region). In contrast, relatively poor model forecast performance is expected on weakly forced days when there are no obvious dynamic forcing mechanisms present to facilitate convective organization.

\section{b. Model diurnal cycle in $P W V$}

Relatively larger moist biases and RMSEs are found at GPS sites located in Mexico than in the United 
TABLE 7. List of strongly forced days and weakly forced days based on the presence of an inverted trough and appreciable TRMM rainfall in northwest Mexico. Because no lateral boundary conditions were unavailable for $7 \mathrm{Jul}$ (marked with asterisk), a weakly forced day, that day was omitted from the analysis. With the exception of $7 \mathrm{Jul}$, there are 22 strongly forced days and 40 weakly forced days during Transect 2013.

\begin{tabular}{lll}
\hline \hline Strongly forced days & \multicolumn{2}{c}{ Weakly forced days } \\
\hline $9 \mathrm{Jul}$ & $26 \mathrm{Jun}$ & $5 \mathrm{Aug}$ \\
$10 \mathrm{Jul}$ & $30 \mathrm{Jun}$ & $9 \mathrm{Aug}$ \\
$12 \mathrm{Jul}$ & $1 \mathrm{Jul}$ & $10 \mathrm{Aug}$ \\
$13 \mathrm{Jul}$ & $2 \mathrm{Jul}$ & $11 \mathrm{Aug}$ \\
$17 \mathrm{Jul}$ & $3 \mathrm{Jul}$ & $12 \mathrm{Aug}$ \\
$18 \mathrm{Jul}$ & $4 \mathrm{Jul}$ & $13 \mathrm{Aug}$ \\
$22 \mathrm{Jul}$ & $5 \mathrm{Jul}$ & $14 \mathrm{Aug}$ \\
$31 \mathrm{Jul}$ & $7 \mathrm{Jul}$ & $18 \mathrm{Aug}$ \\
$1 \mathrm{Aug}$ & $8 \mathrm{Jul}$ & $19 \mathrm{Aug}$ \\
$2 \mathrm{Aug}$ & $11 \mathrm{Jul}$ & $23 \mathrm{Aug}$ \\
$15 \mathrm{Aug}$ & $15 \mathrm{Jul}$ & $24 \mathrm{Aug}$ \\
$16 \mathrm{Aug}$ & $16 \mathrm{Jul}$ & $28 \mathrm{Aug}$ \\
$20 \mathrm{Aug}$ & $23 \mathrm{Jul}$ & $1 \mathrm{Sep}$ \\
$21 \mathrm{Aug}$ & $24 \mathrm{Jul}$ & $6 \mathrm{Sep}$ \\
$22 \mathrm{Aug}$ & $25 \mathrm{Jul}$ & $7 \mathrm{Sep}$ \\
$25 \mathrm{Aug}$ & $26 \mathrm{Jul}$ & $8 \mathrm{Sep}$ \\
$26 \mathrm{Aug}$ & $27 \mathrm{Jul}$ & $9 \mathrm{Sep}$ \\
$27 \mathrm{Aug}$ & $28 \mathrm{Jul}$ & $10 \mathrm{Sep}$ \\
$30 \mathrm{Aug}$ & $29 \mathrm{Jul}$ & $12 \mathrm{Sep}$ \\
$31 \mathrm{Aug}$ & $30 \mathrm{Jul}$ & \\
$3 \mathrm{Sep}$ & $3 \mathrm{Aug}$ & \\
$5 \mathrm{Sep}$ & $4 \mathrm{Aug}$ & \\
\hline
\end{tabular}

States (e.g., MULT) in both the WRF-NAM (Fig. 4) and WRF-GFS (Fig. 5) hindcasts. The largest errors occur at the sites located on the western slope of the SMO (e.g., MULT), where diurnally generated convection transitions to more organized (MCS type) convection during the late afternoon. Thus, the SMO transect has captured weaknesses in the forecast model PWV in the same regions that were noted in the NAME 2004 field campaign dataset (Higgins and Gochis 2007). We later show that these weaknesses in the model PWV fields may also result in rainfall forecast errors. The moist bias is greatest overall in the WRF-NAM hindcasts contributing to a higher number of GPS sites that display statistically significant positive differences in PWV at model initialization. In contrast, the smaller PWV biases in the WRF-GFS hindcasts at model initialization result in fewer GPS sites having statistically significant differences.

We investigate the model initialization of the WRF-NAM hindcasts in greater detail since they display the highest PWV biases and RMSEs (Fig. 4). Nine out of 15 GPS sites show significant positive PWV biases greater than $2 \mathrm{~mm}$ generally west of the SMO crest toward lower elevation. Of the three sites that have a significant positive PWV bias of $0-2 \mathrm{~mm}$, one is located near Phoenix in central Arizona (SA31), another is in extreme southeast Arizona (AZCO), while the final one is located in a relatively dry area east of the SMO crest (CUAH). The highest RMSE values are found on the western SMO slope and foothills with 5-7 mm at MULT, ONVS, and BGTO. The lowest RMSE $(<2 \mathrm{~mm})$ is located at CUAH east of the SMO crest. RMSEs of 2-3 $\mathrm{mm}$ are located in southern Arizona at the same sites that feature the lowest model bias (AZCO and SA31).

As a rule, both the WRF-NAM and WRF-GFS hindcasts (Figs. 4 and 5) show a decrease in bias with time within the diurnal cycle (wet model biases decrease and even become biased dry). MULT is the only SMO transect site that maintains a statistically significant moist model bias throughout the diurnal cycle in both sets of hindcasts. In the WRF-NAM hindcasts (Fig. 4), PSCO is the only site that retains a statistically significant positive PWV bias, increasing from +2 to $+4 \mathrm{~mm}$ at model initialization to +4 to $+6 \mathrm{~mm}$ at $0600 \mathrm{UTC}$ and lasting until the end of the diurnal cycle. The increased moist bias trend with time at PSCO, also in the WRF-GFS hindcasts, is the exception to the overall behavior of the GPS sites in that they typically show increased dry bias (decreased moist bias) throughout the diurnal cycle. The number of sites with statistically significant biases decrease with time correspondingly as the wet biases decrease in the context of the WRF-NAM hindcasts. While statistically significant dry biases of -2 to $0 \mathrm{~mm}$ at BASC (higher elevation) are not observed until 0900 UTC and through the end of the diurnal cycle, statistically significant moist biases of +2 to $+4 \mathrm{~mm}$ are observed at ONVS (lower elevation) at model initialization (1200 UTC) and 1500 UTC. In the WRF-GFS hindcasts (Fig. 5), BASC is the only site with a statistically significant dry bias ( -2 to $0 \mathrm{~mm}$ ) at model initialization and does not become statistically significant again until 0600 UTC through 0900 UTC with values of -2 to $0 \mathrm{~mm}$. The bias then becomes drier with values of -4 to $-2 \mathrm{~mm}$ at the end of the diurnal cycle. Around the same time, lowerelevation ONVS has a statistically significant dry bias of -4 to $-2 \mathrm{~mm}$ from 0900 UTC until 1200 UTC.

\section{c. Model diurnal cycle in rainfall}

The spatially averaged RMSE of daily precipitation accumulation between the WRF hindcasts and each satellite-based rainfall product all fall within the same order of magnitude (Table 8). In additional to being supported by the previous studies mentioned in section $2 \mathrm{~b}$, the choice of TRMM as the primary source of hindcast rainfall verification is also justified by the fact that it has the lowest RMSE with $8.7 \mathrm{~mm} \mathrm{day}^{-1}\left(7.8 \mathrm{~mm} \mathrm{day}^{-1}\right)$ for WRF-NAM (WRF-GFS). The highest RMSE is observed in PERSIANN with $9.9 \mathrm{~mm} \mathrm{day}^{-1}\left(9.2 \mathrm{~mm}\right.$ day $\left.^{-1}\right)$ 
1200 UTC
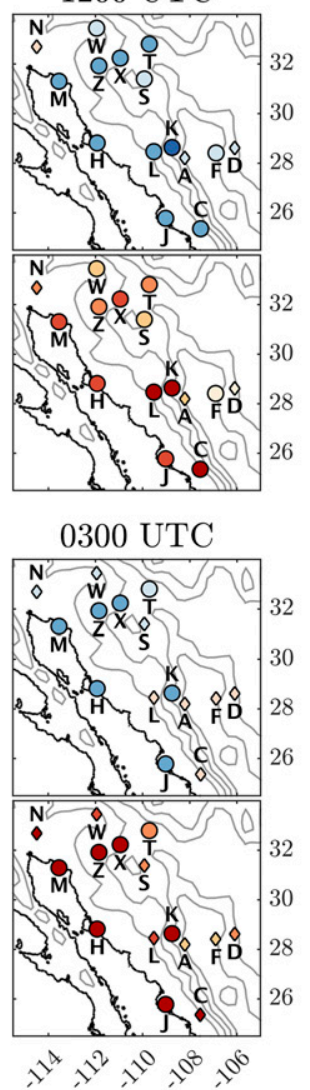

1500 UTC
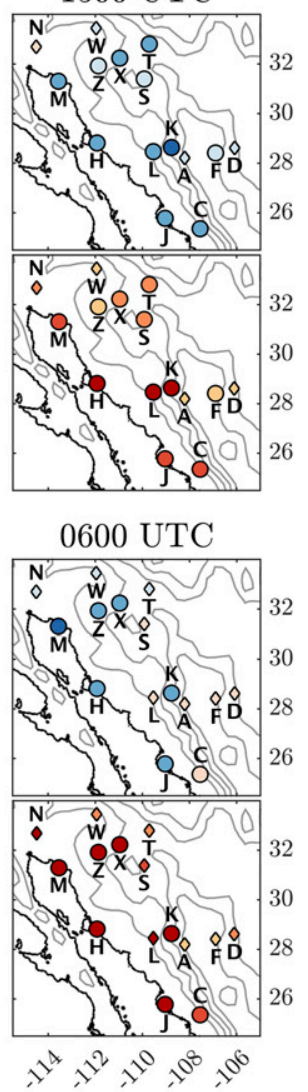
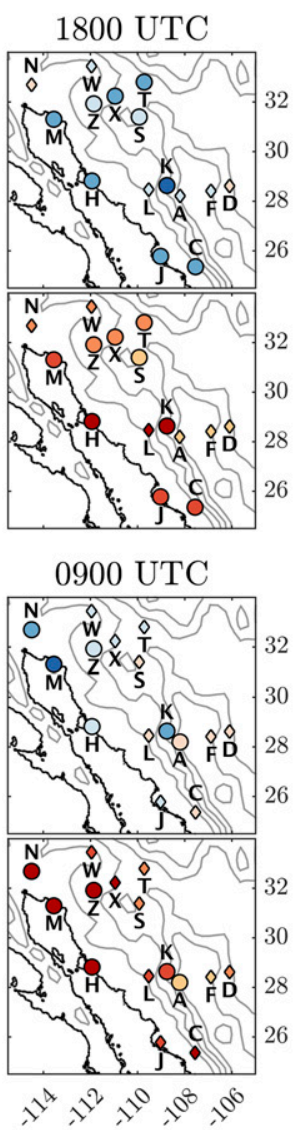
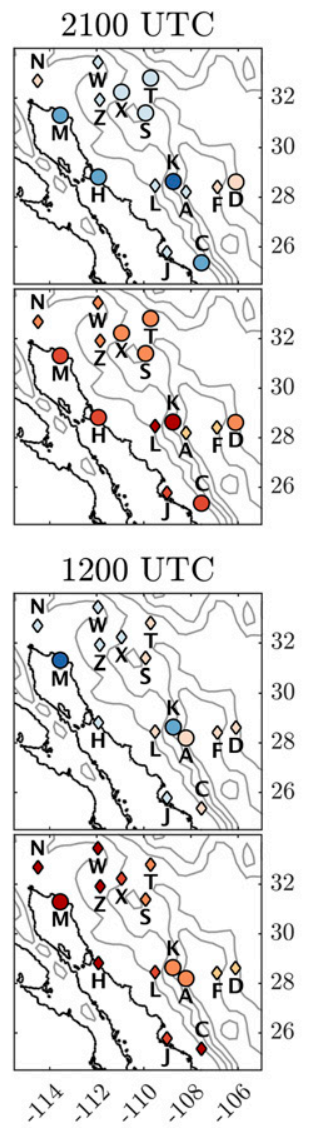

$0000 \mathrm{UTC}$

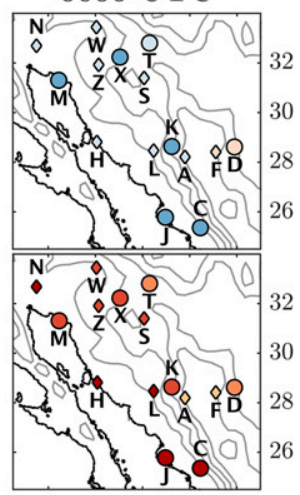

$\begin{array}{ll}\text { BASC } & \text { A } \\ \text { BGTO } & \text { C } \\ \text { CHIH } & \text { D } \\ \text { CUAH } & \text { F } \\ \text { KINO } & \text { H } \\ \text { MOCH } & \text { J } \\ \text { MULT } & \text { K } \\ \text { ONVS } & \text { L } \\ \text { PSCO } & \text { M } \\ \text { SA63 } & \text { N } \\ \text { AZCO } & \text { S } \\ \text { AZSF } & \text { T } \\ \text { SA31 } & \text { W } \\ \text { SA46 } & \text { X } \\ \text { SA48 } & \text { Z }\end{array}$

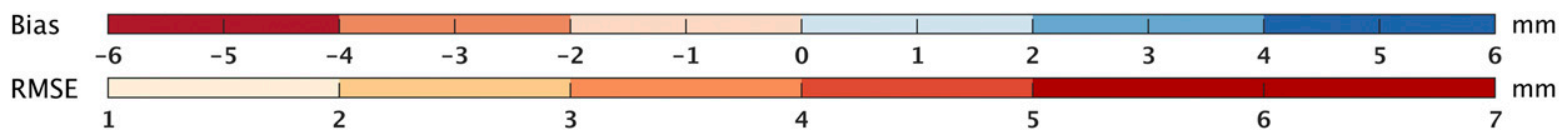

FIG. 4. Mean 3-hourly model bias (top plot of each hour) and RMSE (bottom plot of each hour) of PWV and for all WRF-NAM hindcasts relative to GPS-derived PWV across northwest Mexico and adjacent southwest United States (Transect 2013 and selected SuomiNet stations) within the diurnal cycle. Circles indicate stations with model biases that are statistically significant $(p$ value $<0.01)$. Terrain is contoured every $500 \mathrm{~m}$ (gray lines).

for WRF-NAM (WRF-GFS). For each satellite-based product, the wetter WRF-NAM has a higher RMSE than its respective WRF-GFS RMSE.

In Figs. 6 and 7, we verify the mean diurnal cycle of WRF precipitation that is produced explicitly from the cloud microphysics in d03 (top row) against TRMM (middle row) and display the spatial patterns of the biases (bottom row) in addition to the overall spatially averaged values across the domain (Table 9) for the period of Transect 2013. We normalize the 3- and 24-h hindcast precipitation accumulations into a mean hourly rainfall rate. Because there are no statistically significant differences in spatially averaged rainfall biases between the strongly and weakly forced days, we present the combined set of days where blue (red) areas indicate a wetter (dryer) model bias.
The model-simulated precipitation biases are strongly tied to the evolution of the diurnal cycle of convection. In the WRF-NAM hindcasts (Fig. 6), the precipitation analysis of the diurnal cycle, whose overall positive (moist) PWV bias was mentioned in the previous subsection, correspondingly shows a larger positive (wet) model rainfall bias compared to the WRF-GFS (Fig. 7) as seen through the $2100-0000$ UTC period. WRF-NAM hindcast rainfall begins earlier than the WRF-GFS as seen in the 1200-1500 UTC and 1500-1800 UTC periods (Figs. 6 and 7, left two panels in the top rows). This contributes to the WRF-NAM spatially averaged rainfall model bias both maximizing $3 \mathrm{~h}$ earlier and being greater in magnitude when compared to the WRF-GFS $\left(+0.12 \mathrm{~mm} \mathrm{~h}^{-1}\right.$ at $1800-2100$ UTC for WRF-NAM versus $+0.06 \mathrm{~mm} \mathrm{~h}^{-1}$ at $2100-0000 \mathrm{UTC}$ for WRF-GFS). 

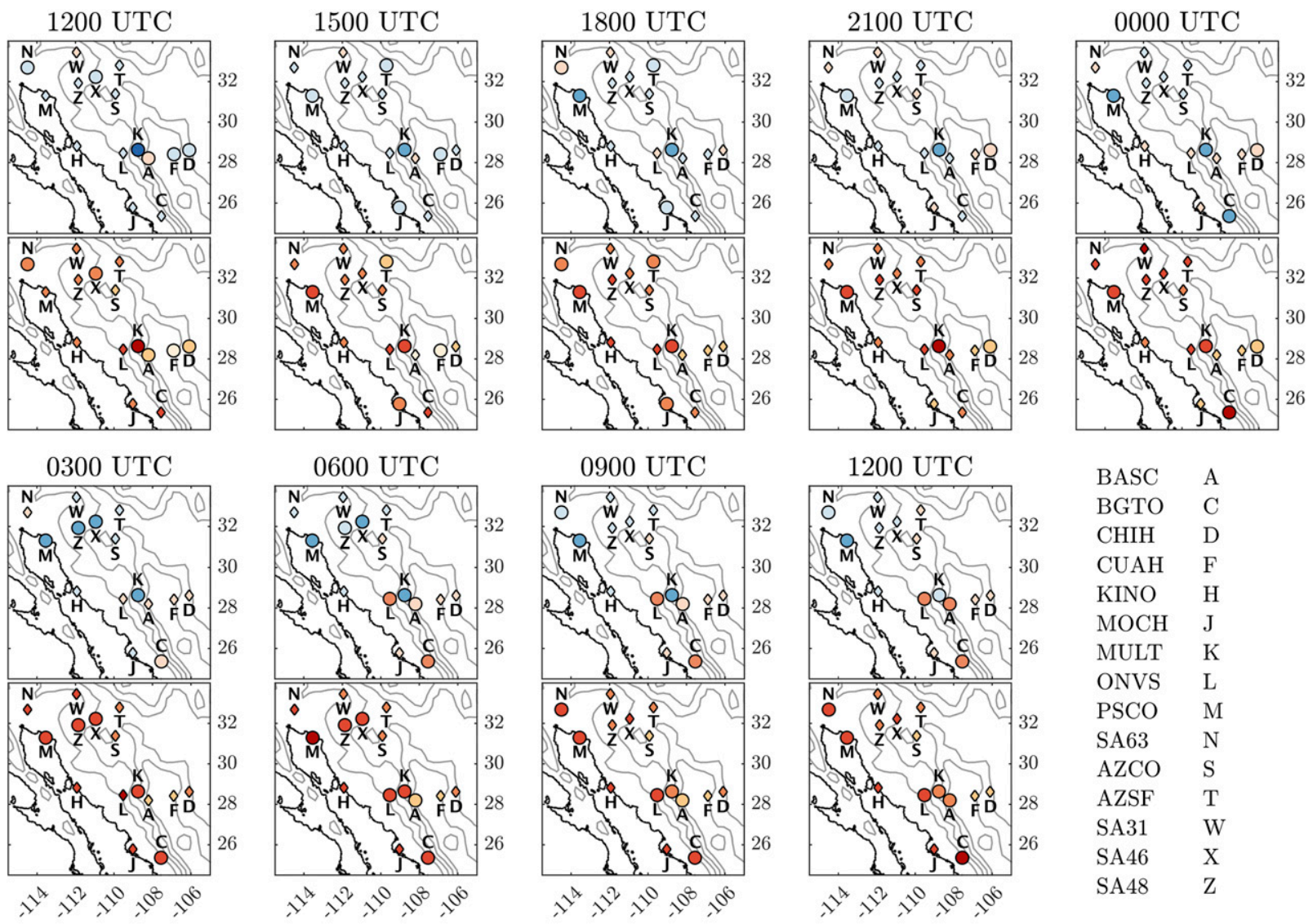

$\begin{array}{ll}\text { BASC } & \text { A } \\ \text { BGTO } & \text { C } \\ \text { CHIH } & \text { D } \\ \text { CUAH } & \text { F } \\ \text { KINO } & \text { H } \\ \text { MOCH } & \text { J } \\ \text { MULT } & \text { K } \\ \text { ONVS } & \text { L } \\ \text { PSCO } & \text { M } \\ \text { SA63 } & \text { N } \\ \text { AZCO } & \text { S } \\ \text { AZSF } & \text { T } \\ \text { SA31 } & \text { W } \\ \text { SA46 } & \text { X } \\ \text { SA48 } & \text { Z }\end{array}$

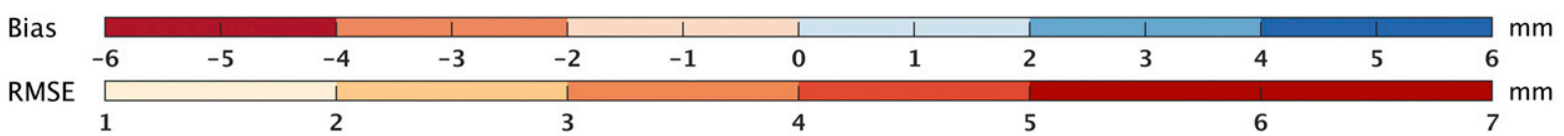

FIG. 5. As in Fig. 4, but for the WRF-GFS hindcasts.

While the spatially averaged TRMM maximizes during the $0000-0300$ UTC period $\left(0.18 \mathrm{~mm} \mathrm{~h}^{-1}\right)$, the spatially averaged modeled precipitation maximizes $3 \mathrm{~h}$ earlier during the 2100-0000 UTC period with $0.28 \mathrm{~mm} \mathrm{~h}^{-1}$ $\left(0.24 \mathrm{~mm} \mathrm{~h}^{-1}\right)$ for WRF-NAM (WRF-GFS) (Table 9). At the time of maximum precipitation bias (1800-2100 UTC for WRF-NAM and 2100-0000 UTC for WRF-GFS), the SMO Transect 2013 sites ONVS, MULT, and BASC (located near the center of each map) coincide with the largest gridpoint-based positive precipitation biases. The spatially averaged precipitation bias is approximately zero by the $0000-0300$ UTC period before minimizing in the $0600-0900$ UTC period $\left(-0.07 \mathrm{~mm} \mathrm{~h}^{-1}\right.$ for WRFNAM and $-0.06 \mathrm{~mm} \mathrm{~h}^{-1}$ for WRF-GFS) and remaining negative (dry) for the remainder of the diurnal cycle. The dry precipitation bias region that begins to appear during the 0000-0300 UTC period is most pronounced just to the north of the ONVS and MULT stations with a smaller area farther south that are both on the western slope of the SMO. The transition from relatively large positive precipitation biases prior to 0000 UTC to relatively large negative precipitation biases after 0300 UTC suggests that WRF is challenged overall in representing the evolution of organized convection in northwest Mexico with respect to timing. A wet model bias (more pronounced in WRF-NAM) is observed in the western slopes of SMO south of the mountain transect sites in the 24-h period. This bias is not seen across the region of MCS activity on

TABLE 8. Grid-based RMSE mean of daily rainfall accumulation $\left(\mathrm{mm} \mathrm{day}^{-1}\right)$ from each satellite-based precipitation product and each hindcast simulation for the duration of Transect 2013. Values are listed in ascending order.

\begin{tabular}{lcc}
\hline \hline \multicolumn{1}{c}{ Product } & WRF-NAM & WRF-GFS \\
\hline TRMM & 8.7 & 7.8 \\
CMORPH & 9.3 & 8.6 \\
GSMap & 9.6 & 8.8 \\
PERSIANN & 9.9 & 9.2 \\
\hline
\end{tabular}



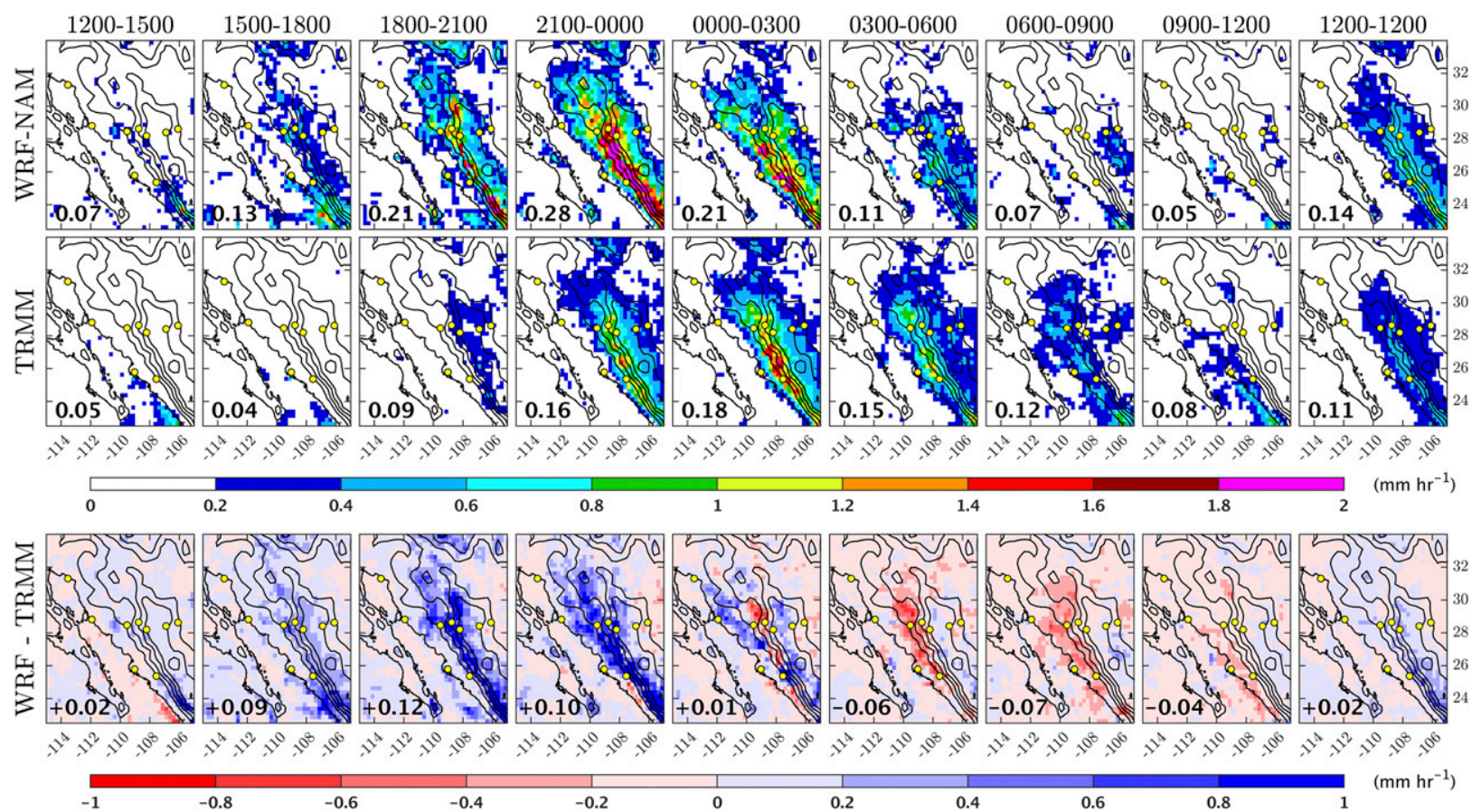

FIG. 6. (top) Mean hourly rainfall rate of WRF-NAM hindcasts, (middle) TRMM precipitation analysis, and (bottom) model bias (WRF minus TRMM) for the combined set of strongly and weakly forced days within diurnal cycle for 3-hourly intervals (columns 1-8) and $24 \mathrm{~h}$ (column 9). The WRF hindcasts were scaled up to the TRMM $0.25^{\circ}$ grid using the "conserve" method of the ESMF software function within NCL. Mean values across all grid boxes for rainfall rate (top two rows) and biases (bottom row) are shown in the bottomleft corner of each map. Blue (red) pixels indicate a wet (dry) model bias. Yellow circles indicate the locations of a subset of the Transect 2013. Terrain is contoured every $500 \mathrm{~m}$ (black lines).

this large time scale because of the canceling effect of the forecast timing error. In summary, regardless of the source of boundary forcing, WRF consistently initiates the convection on the crest of the SMO too early and underestimates the propagating, more MCS-type precipitation that occurs in the afternoon and early evening hours. Our WRF-ARW hindcast results using a convective-permitting grid spacing are broadly similar to the earlier findings of Lee et al. (2007) and Collier and Zhang (2007), who also examined model simulations of the diurnal cycle for the monsoon, although at coarser spatial scales.

\section{d. Evaluation of model performance for rainfall}

We use the CSI, POD, and FAR metrics to evaluate the hindcasts for both strongly forced and weakly forced subsets of days (Figs. 8 and 9). We display the differences of the forecast metrics between the two subsets of days for all but the first 6-h period because convection is limited 1200-1800 UTC (see Fig. 6, row 2). We also perform this analysis for the entire 24-h forecast period (1200-1200 UTC). Blue (red) areas indicate a higher forecast skill for strongly (weakly) forced days. The rank of field statistical significance (pattern correlation of the subdaily grid to the daily grid) is displayed in the lower left (upper right) of each map with both statistics listed in Table 10.

The CSI, POD, and FAR differences display similar spatial patterns within each time period with the POD and FAR having a greater range of difference than the CSI. In the 24-h period, there is a common pattern of greatest CSI and POD and least FAR for the strongly forced days in an area across the high terrain just west of the SMO crest (around BASC) and into lower elevations of Sonora (Figs. 8 and 9, column 4). This area is where convection initiates over the highest terrain and propagates generally toward the west in late afternoon and continues toward the $\mathrm{GoC}$ into the evening and early morning as MCSs. Between the strongly and weakly forced days, the patterns of the differences of CSI and POD are field statistically significant across both the WRFNAM and WRF-GFS hindcasts, while the FAR differences are field statistically significant only in the WRF-GFS during this time.

In the 1800-0000 UTC period, the spatial patterns of the metric differences show increased forecast skill for the strongly forced days across the western SMO slope in the BASC-MULT-ONVS region. In the WRF-GFS hindcasts, the spatial patterns display field statistical 

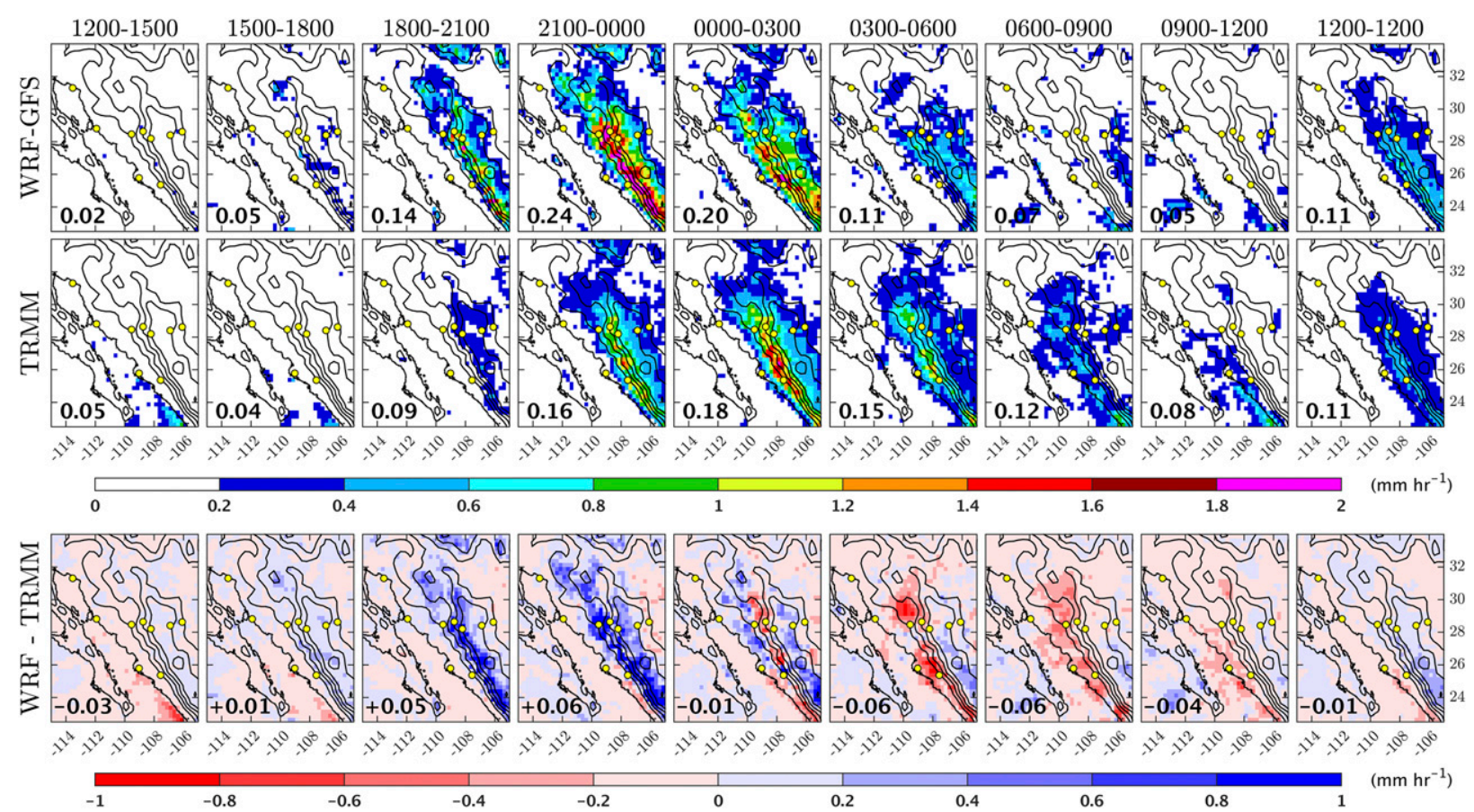

FIG. 7. As in Fig. 6, but for the WRF-GFS hindcasts.

significance and have the highest map correlations with the 24 -h period $(0.55,0.50$, and 0.55 for CSI, POD, and FAR, respectively). In contrast, in the WRFNAM hindcasts, only the CSI difference patterns are field statistically significant while the POD difference pattern is the highest correlated metric to the 24-h period (0.41).

In the 0000-0600 UTC period, we find the lowest ranks of field statistical significance (highest rank is $74.7 \%$ ) indicating that, when the precipitation biases between the WRF and TRMM minimize (Figs. 6 and 7, bottom row) as TRMM precipitation transitions to the lower terrain, the differences in forecast skill has the highest likelihood of occurring by chance. The CSI and
FAR difference patterns in the WRF-NAM at this time have the highest correlations to the 24 -h pattern $(0.43$ and 0.42 , respectively).

In the 0600-1200 UTC period, WRF precipitation is confined to the eastern SMO slope (CUAH-CHIH), near the immediate coast, and over the GoC (Figs. 6 and 7 , top row). The differences of the metrics between the strongly and weakly forced days in the lowest terrain $(<1000 \mathrm{~m})$ of Sonora is minimal $( \pm 0.1)$. The CSI and FAR difference patterns are field statistically significant in both the WRF-NAM and WRF-GFS, while the POD difference patterns are field statistically significant only in the WRF-NAM. In the WRF-NAM hindcasts, the strongly forced days have highest forecast verification

TABLE 9. Mean grid precipitation rate for TRMM, WRF-NAM, WRF-GFS, and model bias (WRF minus TRMM) for the diurnal cycle $\left(\mathrm{mm} \mathrm{h}^{-1}\right)$ for 3- and 24-h intervals of the hindcasts during the Transect 2013 period. Highest hourly mean precipitation rate and model biases are in bold.

\begin{tabular}{lccccc}
\hline \hline Time (UTC) & TRMM & WRF-NAM & WRF-NAM bias & WRF-GFS & WRF-GFS bias \\
\hline $1200-1500$ & 0.05 & 0.07 & +0.02 & 0.02 & 0.05 \\
$1500-1800$ & 0.04 & 0.13 & +0.09 & 0.14 & +0.03 \\
$1800-2100$ & 0.09 & 0.21 & $\mathbf{+ 0 . 1 2}$ & $\mathbf{0 . 2 4}$ & +0.01 \\
$2100-0000$ & 0.16 & $\mathbf{0 . 2 8}$ & +0.10 & 0.20 & +0.05 \\
$0000-0300$ & $\mathbf{0 . 1 8}$ & 0.21 & -0.01 & 0.07 & -0.01 \\
$0300-0600$ & 0.15 & 0.07 & -0.07 & 0.05 & -0.06 \\
$0600-0900$ & 0.12 & 0.05 & -0.04 & 0.11 & -0.04 \\
$0900-1200$ & 0.08 & 0.14 & +0.02 & -0.01 \\
$1200-1200$ & 0.11 & &
\end{tabular}




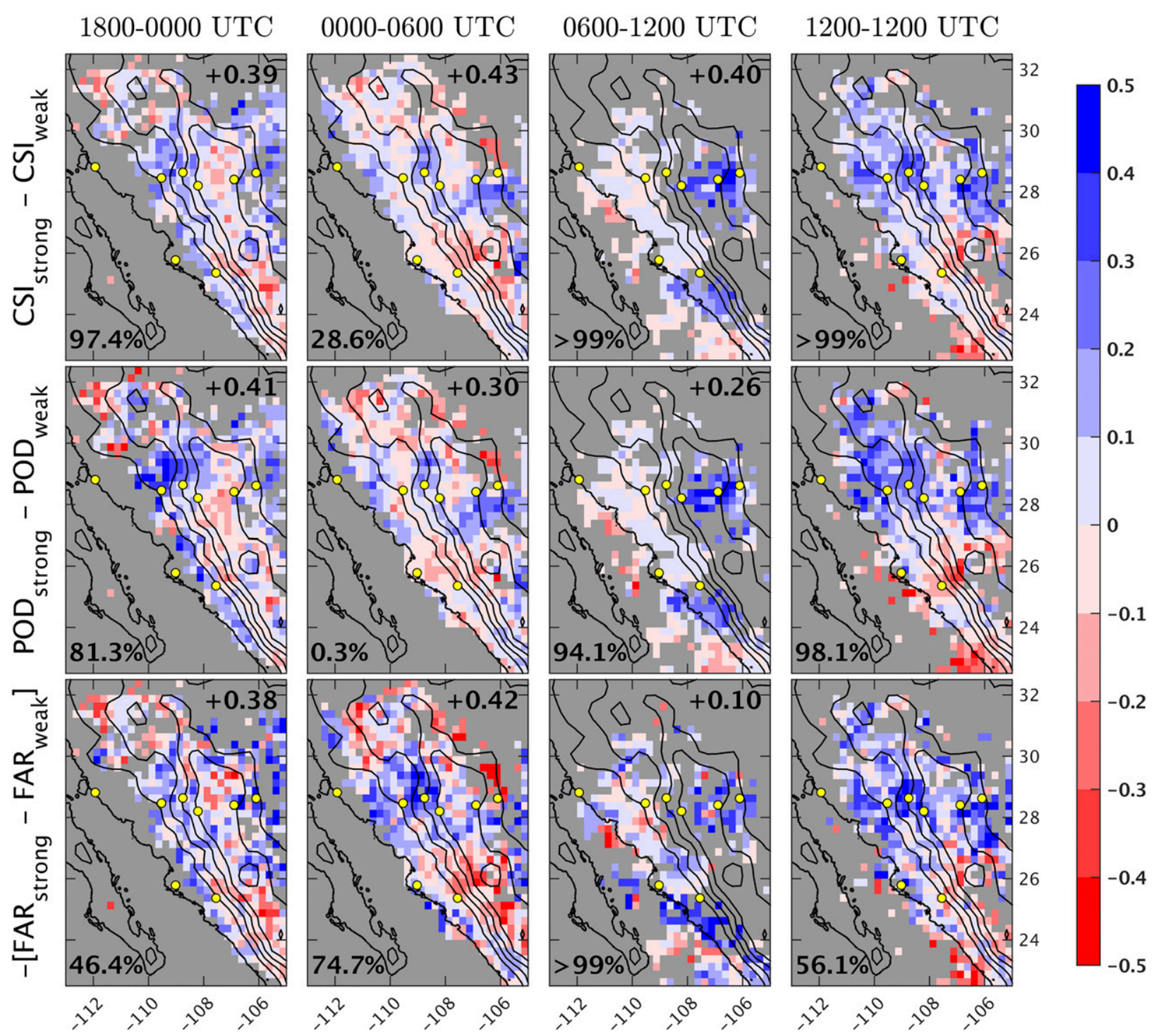

FIG. 8. Differences between the strongly and weakly forced days of grid-based (top) CSI, (middle) POD, and (bottom) FAR forecast verification metrics for WRF-NAM hindcasts (modeled) and TRMM (observed) rainfall for the 1800-0000 UTC (column 1), 0000-0600 UTC (column 2), 0600-1200 UTC (column 3), and 1200-1200 UTC (daily) (column 4) periods. Increased forecast skill is shown in red (blue) for the strongly (weakly) forced days. Gray pixels indicate where metrics could not be computed. See text for metrics description and local significance methodology. The statistical field significance rank of each map is displayed in the bottom-left corner of each map and was obtained via 1000 permutations in a Monte Carlo resampling technique. The pattern correlation of metric between the subdaily (columns 1-3) and daily (column 4) forecast metric is given in the top-right corner of each subdaily map. Yellow circles indicate the locations of a subset of Transect 2013. Terrain is contoured every $500 \mathrm{~m}$ (black lines).

metrics south of MOCH-BGTO (tropical related) along the coast and in the northern SMO and east slope (BASC-CUAH-CHIH). The WRF-GFS hindcasts show the highest skill in the strongly forced days across eastern SMO slope in the CSI and POD difference maps.

In the 1800-0000 UTC and 24-h periods, the strongly forced days display higher precipitation forecast skill than the weakly forced days in all or some of the three metrics that are field statistically significant. This includes areas across west of the SMO crest, western
SMO foothills, and toward the GoC where MCSs mature and decay and supports the idea that the WRF simulations in the weakly forced days are more challenged to capture the mature stages of MCSs once they propagate off the western slopes of the SMO. This finding is consistent with our hypothesis that MCS development in WRF will tend to more preferentially occur when an IV is nearby and conversely WRF is more challenged to forecast MCS development in the absence of an IV. 


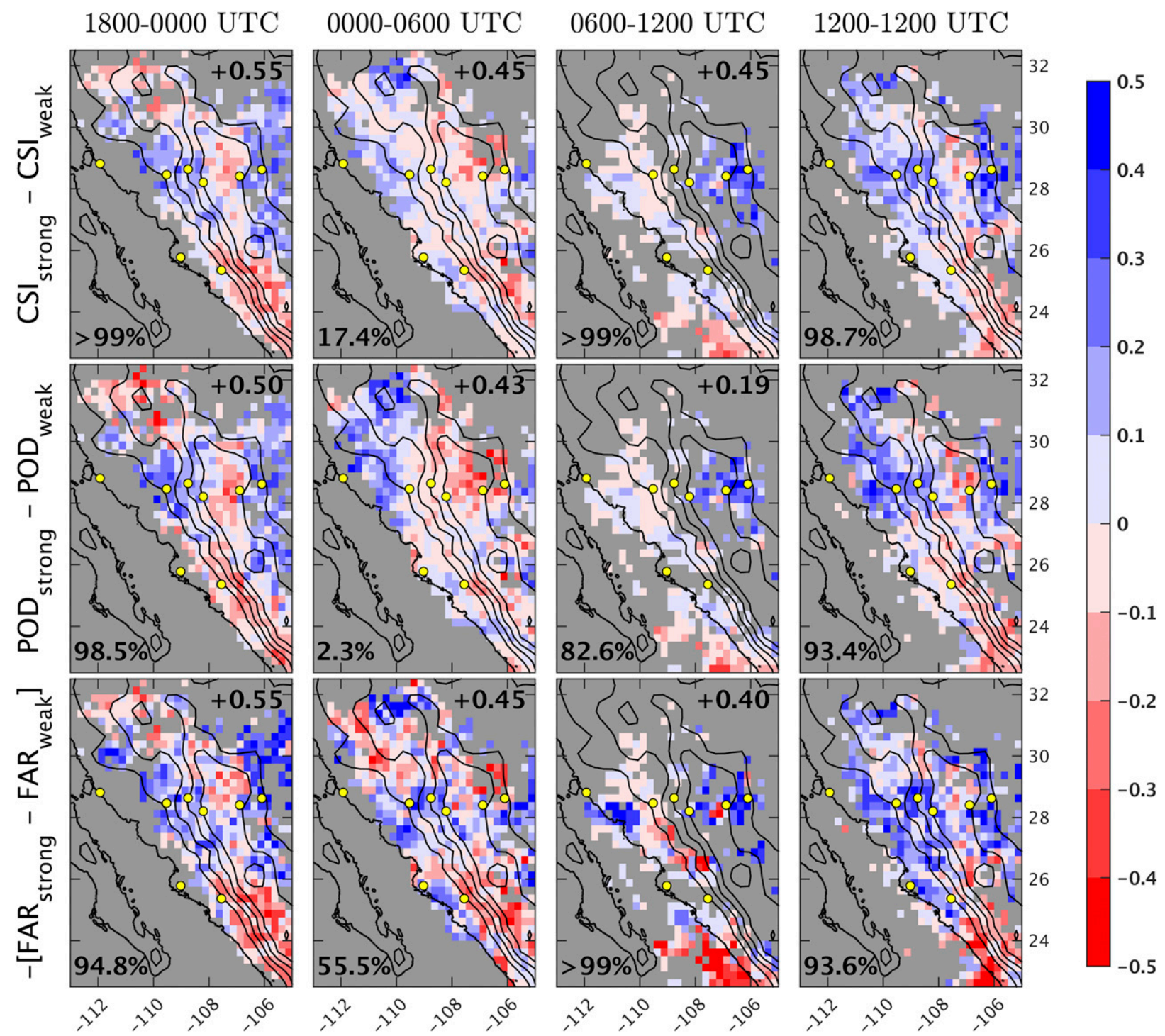

FIG. 9. As in Fig. 8, but forecast metrics calculated for the WRF-GFS hindcasts.

There is some agreement, in terms of spatial patterns, in the rainfall verification metrics among the four satellitebased precipitation datasets. This is showcased in the differences in daily $(24 \mathrm{~h})$ forecast verification metrics between the strongly forced days and weakly forced days for WRF-NAM (WRF-GFS) in Fig. 10 (Fig. 11) using TRMM, CMORPH, PERSIANN, and GSMaP. Additionally, CSI (CSI and FAR) differences in the WRF-NAM (WRFGFS) have field statistical significance across all products.

\section{Case study of 8-10 July 2013}

\section{a. Synoptic overview}

An IV approached from the east and across the SMO in conjunction with the second major gulf surge of the season triggered by TC Erick on 8 July 2013. Based on our classification criteria, the first day (8-9 July) is considered weakly forced while the second day (9-10 July) is considered strongly forced. GOES water vapor IR imagery depicted a mature MCS cloud shield each evening at approximately 0600 UTC in similar locations over northern Sonora and the immediate border region of southern Arizona (Fig. 12, top panel). Pressure and winds on the 2.0 potential vorticity unit (PVU) surface indicate the location of the IV as shown by a PV anomaly at 1800 UTC from the 1200 UTC GFS 6-h forecast (Fig. 12, bottom panel). Rising motion from the upward tilting of isentropes ahead of the PV anomaly was closer to the area of the MCS development on the second day. 
TABLE 10. For both the WRF-NAM (top) and WRF-GFS (bottom) hindcasts, field significance values of the differences in forecast metrics between the two subsets of strongly and weakly forced days are listed. Field significance levels that are greater than $90 \%$ are in bold and those between $80 \%$ and $90 \%$ are in italics. Also, pattern correlations between the subdaily and daily grids are shown with the greatest pattern correlation in bold.

\begin{tabular}{|c|c|c|c|c|c|c|}
\hline \multirow[b]{2}{*}{ Time (UTC) } & \multicolumn{2}{|c|}{$\mathrm{CSI}_{\text {strong }}-\mathrm{CSI}_{\text {weak }}$} & \multicolumn{2}{|c|}{$\mathrm{POD}_{\text {strong }}-\mathrm{POD}_{\text {weak }}$} & \multicolumn{2}{|c|}{$\mathrm{FAR}_{\text {strong }}-\mathrm{FAR}_{\text {weak }}$} \\
\hline & $\begin{array}{c}\text { Field } \\
\text { significance level }\end{array}$ & $\begin{array}{c}\text { Pattern correlation } \\
\text { to daily }\end{array}$ & $\begin{array}{c}\text { Field significance } \\
\text { level }\end{array}$ & $\begin{array}{l}\text { Pattern correlation } \\
\text { to daily }\end{array}$ & $\begin{array}{c}\text { Field significance } \\
\text { level }\end{array}$ & $\begin{array}{c}\text { Pattern correlation } \\
\text { to daily }\end{array}$ \\
\hline \multicolumn{7}{|l|}{ WRF-NAM } \\
\hline $1800-0000$ & $97.4 \%$ & +0.39 & $81.3 \%$ & +0.41 & $46.4 \%$ & +0.38 \\
\hline 0000-0600 & $28.6 \%$ & +0.43 & $0.3 \%$ & +0.30 & $74.7 \%$ & +0.42 \\
\hline 0600-1200 & $>99 \%$ & +0.40 & $94.1 \%$ & +0.26 & $>99 \%$ & +0.10 \\
\hline $1200-1200$ & $>99 \%$ & & $98.1 \%$ & & $56.1 \%$ & \\
\hline \multicolumn{7}{|l|}{ WRF-GFS } \\
\hline $1800-0000$ & $>99 \%$ & +0.55 & $98.5 \%$ & +0.50 & $94.8 \%$ & +0.55 \\
\hline 0000-0600 & $17.4 \%$ & +0.45 & $2.3 \%$ & +0.43 & $55.5 \%$ & +0.45 \\
\hline 0600-1200 & $>99 \%$ & +0.45 & $82.6 \%$ & +0.19 & $>99 \%$ & +0.40 \\
\hline $1200-1200$ & $98.7 \%$ & & $93.4 \%$ & & $93.6 \%$ & \\
\hline
\end{tabular}

At 1200 UTC 8 July, an IV was located south of Big Bend, Texas, and was moving west into the Mexican state of Chihuahua as shown on the dynamic tropopause map (Fig. 12, bottom left). The lowest pressure indicated by the 6-h GFS forecast of the associated PV anomaly was between 280 and $300 \mathrm{hPa}$. GOES infrared imagery showed convective clouds near the southern tip of the Baja California Peninsula in association with TC Erick, which triggered a gulf surge at the mouth of the GoC earlier in the day that was observed by all 3 transect sites and Yuma. As shown in the 3-hourly GOES IR and TRMM accumulations (Fig. 13, rows 1 and 2), thunderstorms developed along the Sonora-Chihuahua border along the northern SMO crest at approximately 2100 UTC 8 July. By 0000 UTC 9 July, an MCS began to form near ONVS-MULT-BASC. Between 0300 and 0600 UTC, rainfall maximized in intensity with a large 3-h accumulation swath of $20 \mathrm{~mm}$ north of ONVS. A mature MCS evident by a vast cloud shield over Sonora at 0600 UTC began to dissipate by 0900 UTC. While the synoptic lift from the IV was not likely playing a role in the development of the MCS because of its distance, the $20-25-\mathrm{kt}\left(1 \mathrm{kt}=0.51 \mathrm{~m} \mathrm{~s}^{-1}\right)$ east winds above $200 \mathrm{mb}$ over the northern SMO likely created favorable vertical wind shear for the formation and maintenance of the MCS.

After lingering convection and debris clouds at 1500 UTC (Fig. 14, top row), the following strongly forced day is similar in terms of the MCS formation and location. It is classified as strongly forced because at 1200 UTC 9 July the IV was located on the eastern border of the Tier I region (core) and therefore had more influence than on the previous day despite the PV anomaly being weaker (one grid point with 260-280 hPa). Its location directly over the northern SMO at 1800 UTC (Fig. 12, bottom right) aided in upward motion and wind shear for the MCS that would form just to the west. TRMM precipitation (Fig. 14, row 2) showed that diurnal convection began approximately three hours earlier than the previous day at 1800 UTC near CUAH just east of the SMO crest in association with the IV. By 2100 UTC, convection in the northern SMO was in a similar region to the previous evening, but with greater spatial extent. Between 0300 and 0600 UTC 10 July, the 3-h rainfall accumulation maximized at the same time as the day before but with a larger 20-mm swath that is also shifted north and west at a location around $\mathrm{MOCH}$ and toward the northeast into southern Arizona. By 0600 UTC, the MCS cloud shield reached maximum coverage similar to the previous day. A small $20-\mathrm{mm}$ swath is apparent in the next 3-h period near the border region, but after 0900 UTC the MCS cloud shield quickly dissipated. Only lingering showers were present between PSCO and Yuma at 1200 UTC.

\section{b. Evaluation of model hindcast precipitation}

Here, we illustrate the importance of synoptic forcing to MCS development in existing models and WRF. The 24-h rainfall accumulations across all four satellitebased rainfall products display roughly similar rainfall patterns of the MCSs that had occurred each evening and night, but the magnitudes were different (Fig. 15). TRMM (PERSIANN) gives the lowest (highest) rainfall accumulations for both days. For 9 July 2013 (Fig. 15, bottom row), the large 90 -mm isohyet in PERSIANN (and to a less extent, CMORPH) is likely an overestimate that may have been contaminated by the high IR brightness from the massive anvil. PERSIANN is also the only product that does not include gauge bias correction. 

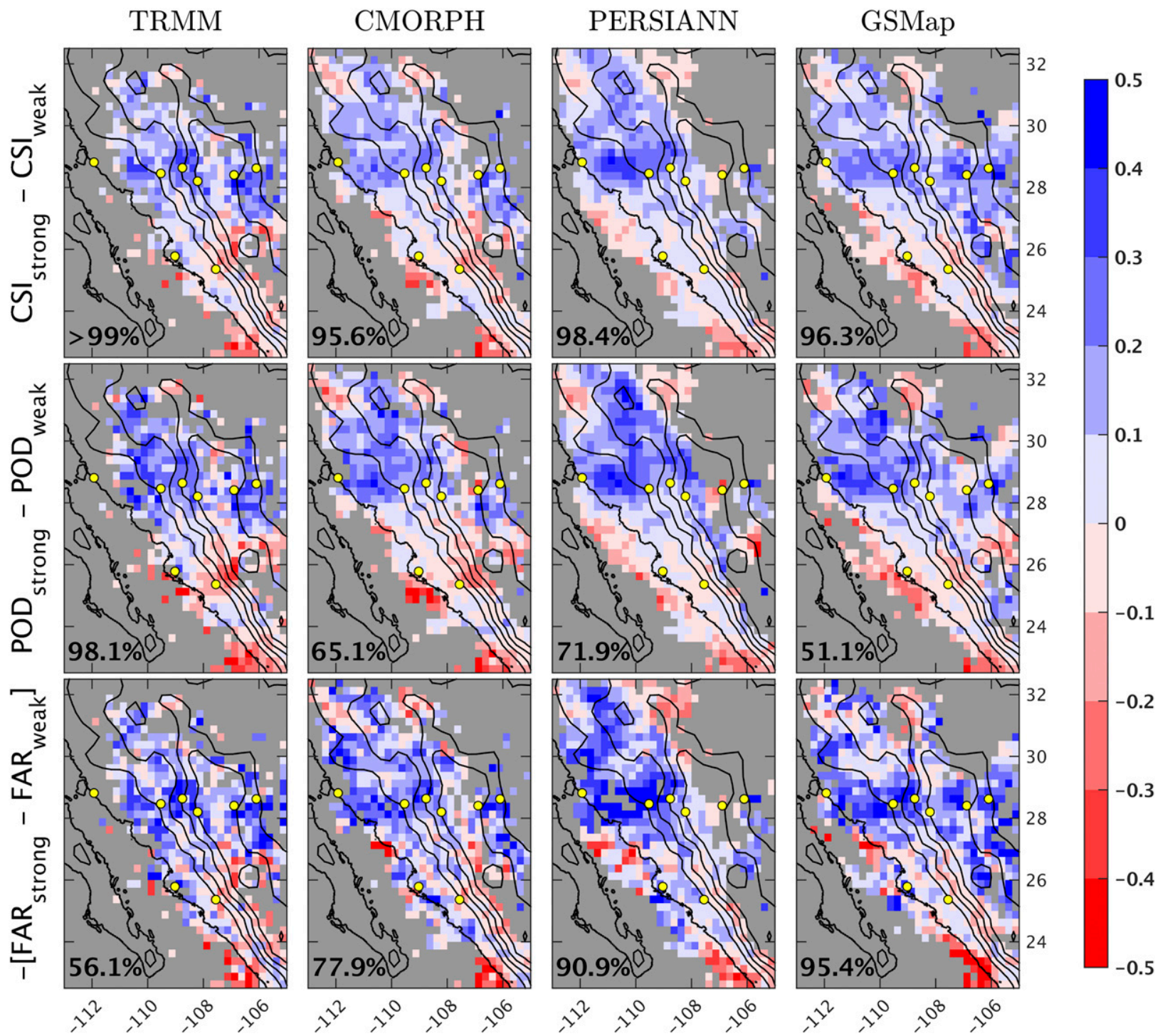

FIG. 10. Differences between the strongly and weakly forced days of grid-based daily rainfall forecast verification metrics for WRFNAM hindcasts and each satellite-based precipitation product of TRMM (column 1), CMORPH (column 2), PERSIANN (column 3), and GSMap (column 4). The metrics include (top) CSI, (middle) POD, and (bottom) FAR. See Fig. 8 caption for description and text for complete methodology.

Figure 16 displays the 24-h precipitation accumulation from the model providing the lateral boundary conditions (columns 2 and 4), their respective WRF simulations (columns 3 and 5), and TRMM (column 1) for both the weakly forced day (top row) and strongly forced day (bottom row). The coarse resolution of the parent models requires cumulus parameterization, as they cannot represent precipitation explicitly as is apparent in the precipitation accumulation pattern. TRMM shows MCS-related precipitation of upward of $20-50 \mathrm{~mm}$ (yellow, orange, and red) over a large portion of northern Sonora on the weakly forced day. While the NAM model shows a closed 10-mm isohyet north of the MCS maximum precipitation area, the GFS model shows a small closed 20-mm isohyet on the western edge of this region.

The respective WRF-NAM shows a semblance of the NAM model precipitation pattern in northern Sonora, but the WRF-GFS has does not replicate the GFS model precipitation area in central Sonora. The weakly forced day displayed poor WRF performance in terms of MCS location and timing (Fig. 13, rows 3-4). A large area of rainfall with accumulations of greater than $20 \mathrm{~mm}$ in WRF-NAM begins 1800-2100 UTC just west of the crest in the southern SMO around and south of BGTO. 

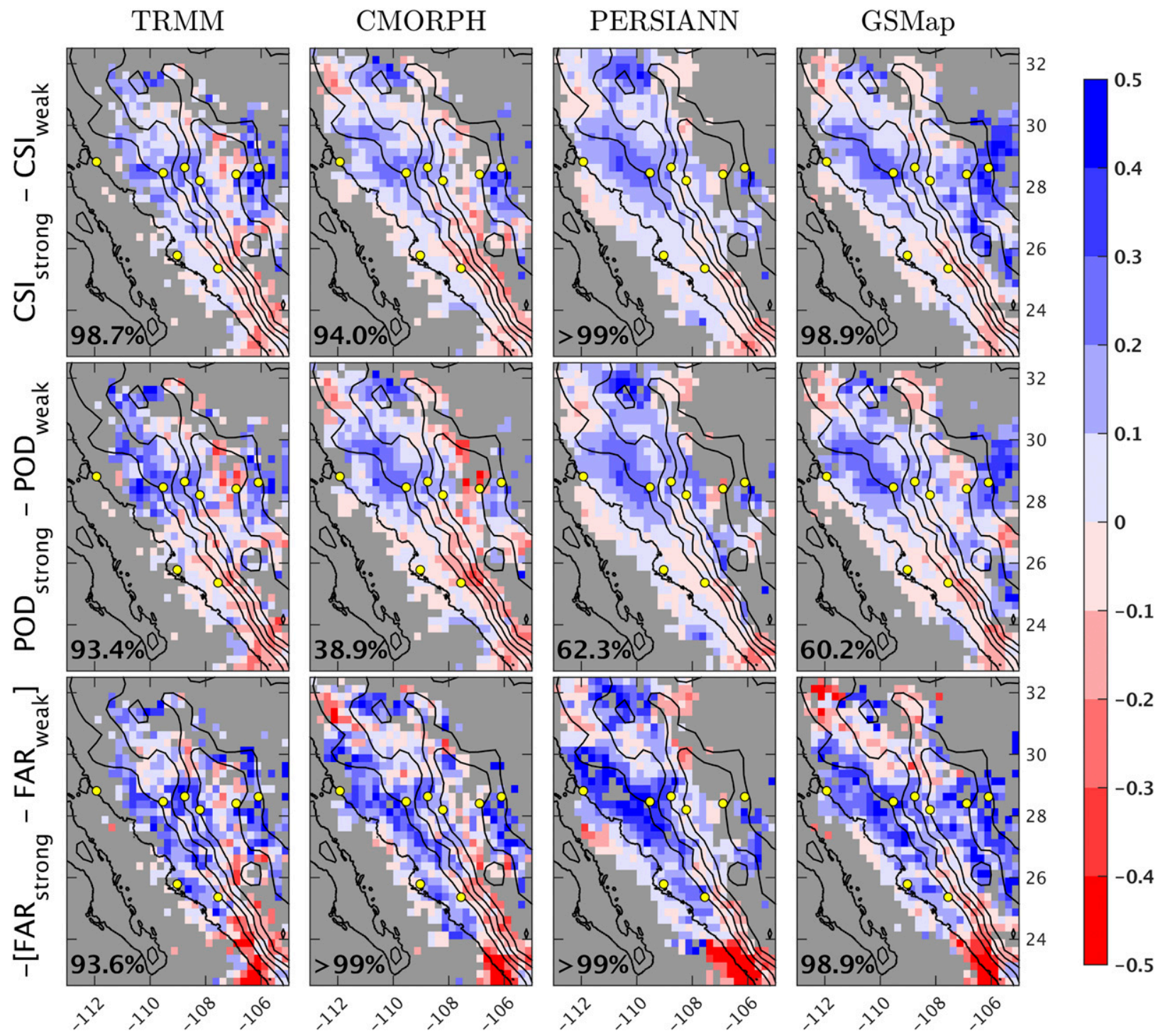

FIG. 11. As in Fig. 10, but forecast metrics calculated for the WRF-GFS hindcasts.

TRMM at the same time showed accumulations of no more than $6 \mathrm{~mm}$. This swath expanded into the northern SMO toward MULT by 2100-0000 UTC. The WRF-GFS demonstrates a similar pattern, but with less intensity. At 0300-0600 UTC, the WRF-NAM indicated convection south of ONVS-MULT-BASC, while TRMM showed the MCS occurring north of there. By 0600-0900 UTC, the WRF-GFS shows an area of rainfall in the same region as the WRF-NAM $3 \mathrm{~h}$ earlier. Both parent models and their respective WRF simulations show precipitation along the SMO from central Sonora south that is not observed in the TRMM. For the strongly forced day, a larger area of $20-50-\mathrm{mm}$ accumulation is shown in central Sonora close to the Arizona border region from the MCS. WRF precipitation developed rapidly prior to 2100 UTC from the central SMO into southern Arizona and continued through 0000 UTC near the Arizona border near the area of TRMM rainfall, although it was 3-6h too early (Fig. 14, rows 3-4). At 2100-0000 UTC, a large rainfall swath greater than $20 \mathrm{~mm}$ was shown at lower elevations west of MULT in both WRF-NAM and WRF-GFS for the strongly forced day as the model advances the precipitation off the SMO too quickly. By 0000-0300 UTC, the 20-mm swath was located near KINO close to the actual MCS location. After this time, the WRF-GFS performed relatively well in simulating the MCS near its actual location through 0900 UTC with 3-h swaths of rainfall greater than $20 \mathrm{~mm}$ that matched the timing of TRMM. In contrast to the weakly forced day, the rainfall patterns of the parent 


\section{Weakly-forced}
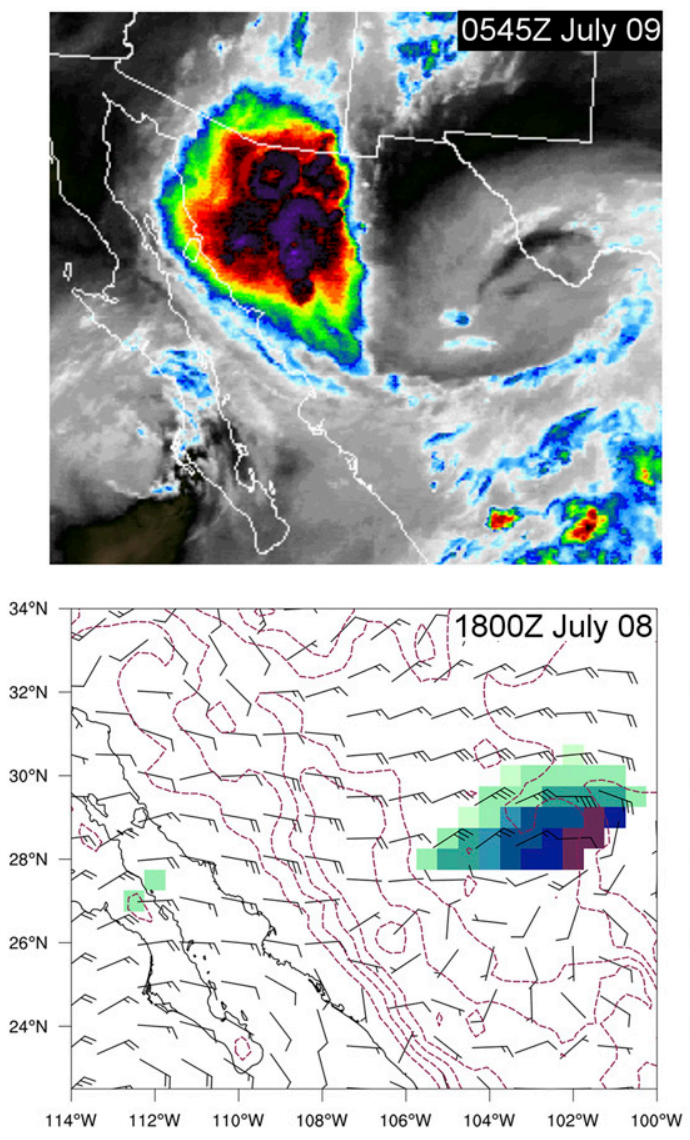

Strongly-forced
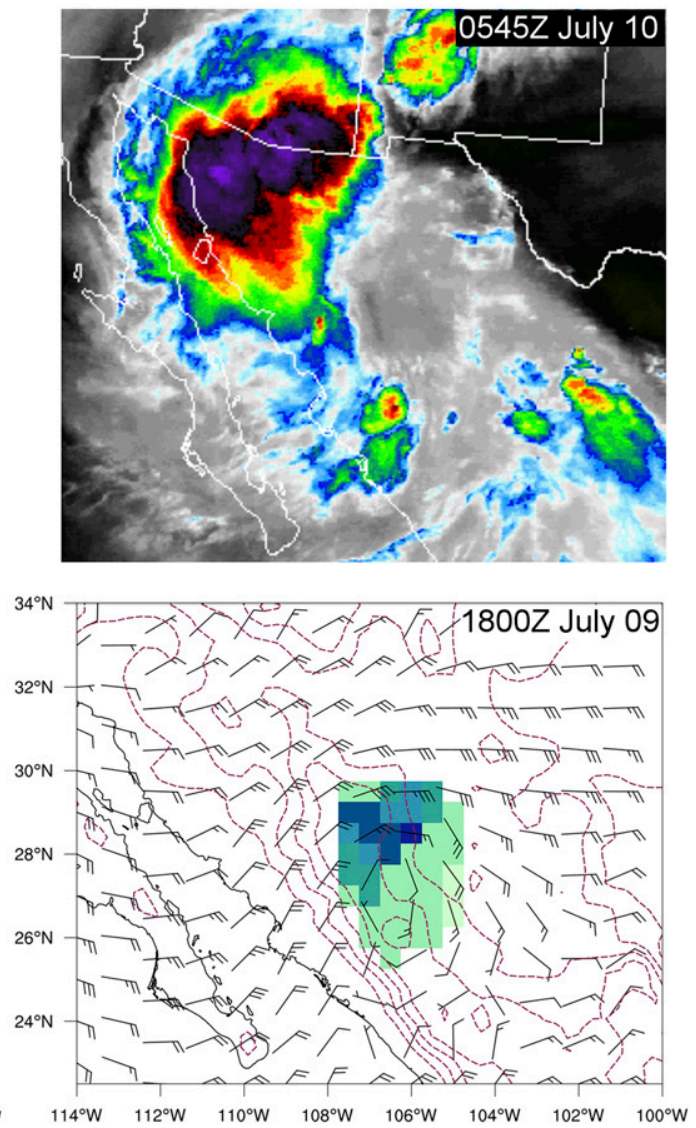

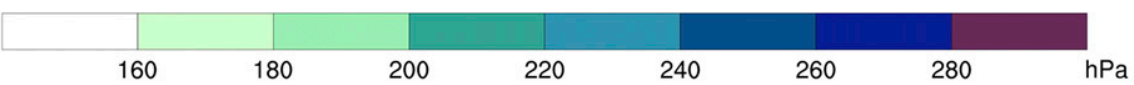

FIG. 12. (bottom) Pressure (shaded every $20 \mathrm{hPa}$ below $160 \mathrm{hPa}$ ) and winds (kt) are displayed on the $2.0 \mathrm{PVU}$ surface (dynamic tropopause) for the 6-h 1200 UTC GFS forecast valid at 1800 UTC with terrain contoured every $500 \mathrm{~m}$ (purple dashed lines). (top) Approximately $12 \mathrm{~h}$ later (0545 UTC), the observed water vapor IR channel from GOES satellite. These maps are shown for a (left) weakly forced and (right) strongly forced day composing the 8-10 Jul 2013 case study.

models and their respective WRF simulation are similar in nature and cover the general location of the MCS observed in TRMM. Similar to the weakly forced day, there is still there is an overforecast of rainfall in the WRF simulations (especially WRF-NAM) south of the MCS locations along the SMO, reflecting the erroneous early initiation of convective precipitation and positive modeled precipitation biases early in the day, as discussed above in reference to Figs. 6 and 7.

\section{Discussion}

In both WRF-NAM and WRF-GFS hindcasts, regardless of the strong or weak classification criteria, relatively large positive biases in modeled simulated PWV occur on the western slopes of the northern SMO during the first part of the day (prior to 0000 UTC). These moist biases likely contribute to an erroneous model representation of the diurnal cycle of convection that initiates $3-6 \mathrm{~h}$ earlier than observed in TRMM; simulated convective rainfall is too high prior to 0000 UTC and too low after 0300 UTC. MCS-type convection is more likely to occur in the latter period. These same types of systematic errors in the modeled representation of the diurnal cycle of convection have also been noted in prior studies modeling North American monsoon precipitation using a coarser resolution with parameterized convection. 

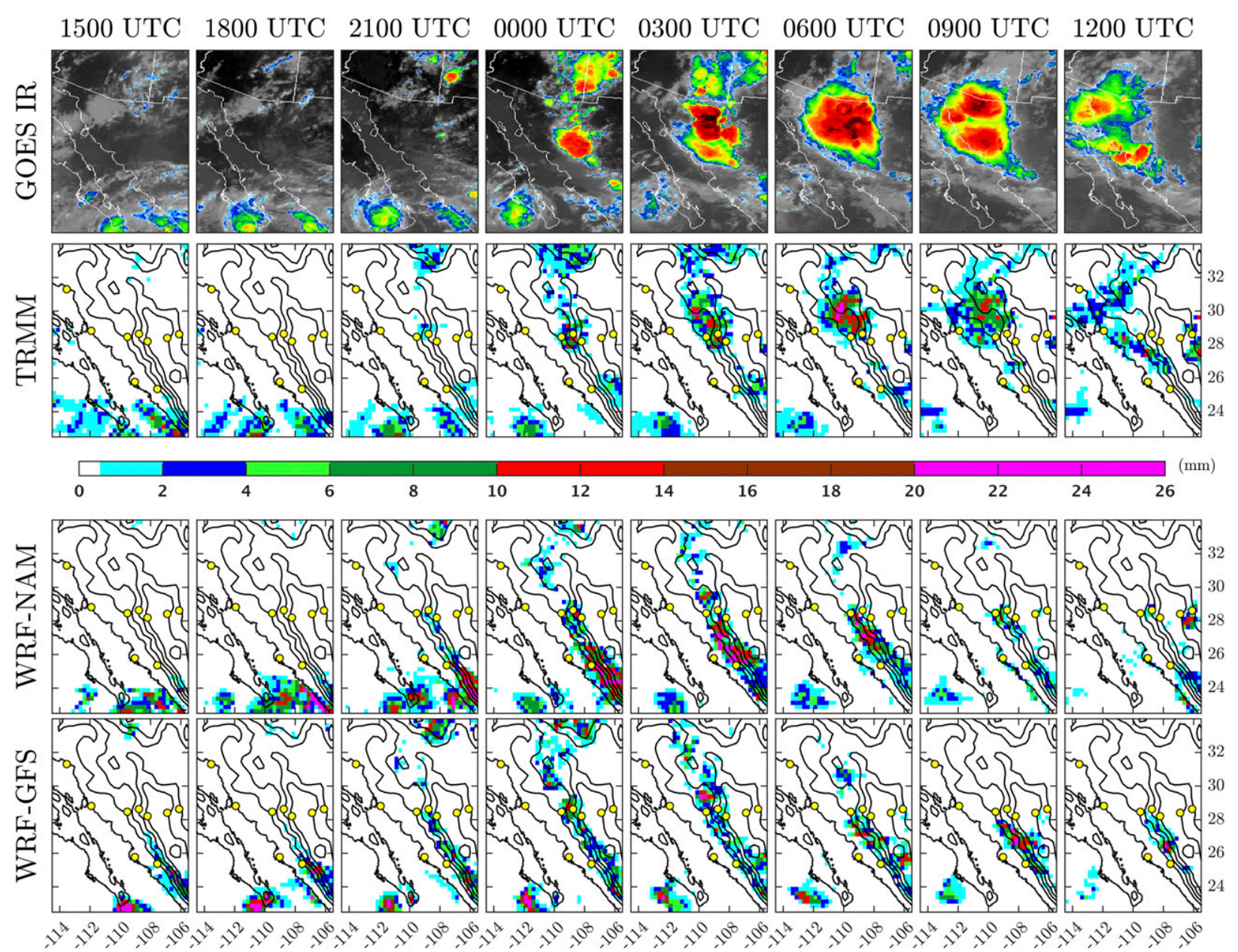

FIG. 13. 3-hourly GOES IR (11- $\mu \mathrm{m}$ channel) imagery (row 1), 3-h rainfall accumulation of TRMM (row 2), WRF-NAM hindcast (row 3), and WRF-GFS hindcast (row 4) for the weakly forced day of 8 Jul 2013. Times are in UTC and indicate the time of the GOES IR image and the ending time of the 3-h rainfall accumulation. Yellow circles indicate the locations of a subset of Transect 2013 . Terrain is contoured every $500 \mathrm{~m}$ (black lines).

Given the relative poor performance of the WRF Model for organized MCS-type convection during the weakly forced days without the appreciable influence of an IV, we hypothesize that the convective-permitting WRF Model simulations would potentially benefit the most from the assimilation of GPS-PWV observations in these types of days. This hypothesis is well supported by an ensemble-based model sensitivity analysis of the 8-10 July 2013 case study that included a weakly forced day followed by a strongly forced day. The sensitivity of model-simulated PWV and rainfall relative to the initial PWV specification at ONVS for the weakly forced day (8-9 July 2013) and strongly forced day (9-10 July 2013) is shown in Fig. 17 with the methodological approach described in appendix A. The ONVS Transect 2013 site was chosen in this analysis for the following reasons: 1) its location west of the crest of the SMO approximately corresponds to where the transition to organized MCStype convection occurs during these particular days, 2) it exhibits the largest relative biases and RMSE in modeled simulated PWV within the SMO transect, and 3) its location at model initialization is far enough upstream to be a source of moisture feeding the convection that would commence along the SMO crest approximately $6 \mathrm{~h}$ later owing to diurnal mountain/valley-breeze circulation. Other sites closer to the SMO crest (i.e., MULT and BASC) do not appear to have a large PWV "memory" indicated by the lower sensitivities there (not shown). At the model initialization and 12-h forecast times (left two panels of Fig. 17, respectively), we find clear higher sensitivity of the modeled simulated PWV to specification of PWV initial conditions at this site for the weakly forced day than for the strongly forced day. This results in relatively high sensitivity of the 

1800 UTC 2100 UTC 0000 UTC

0300 UTC

0600 UTC

0900 UTC

1200 UTC
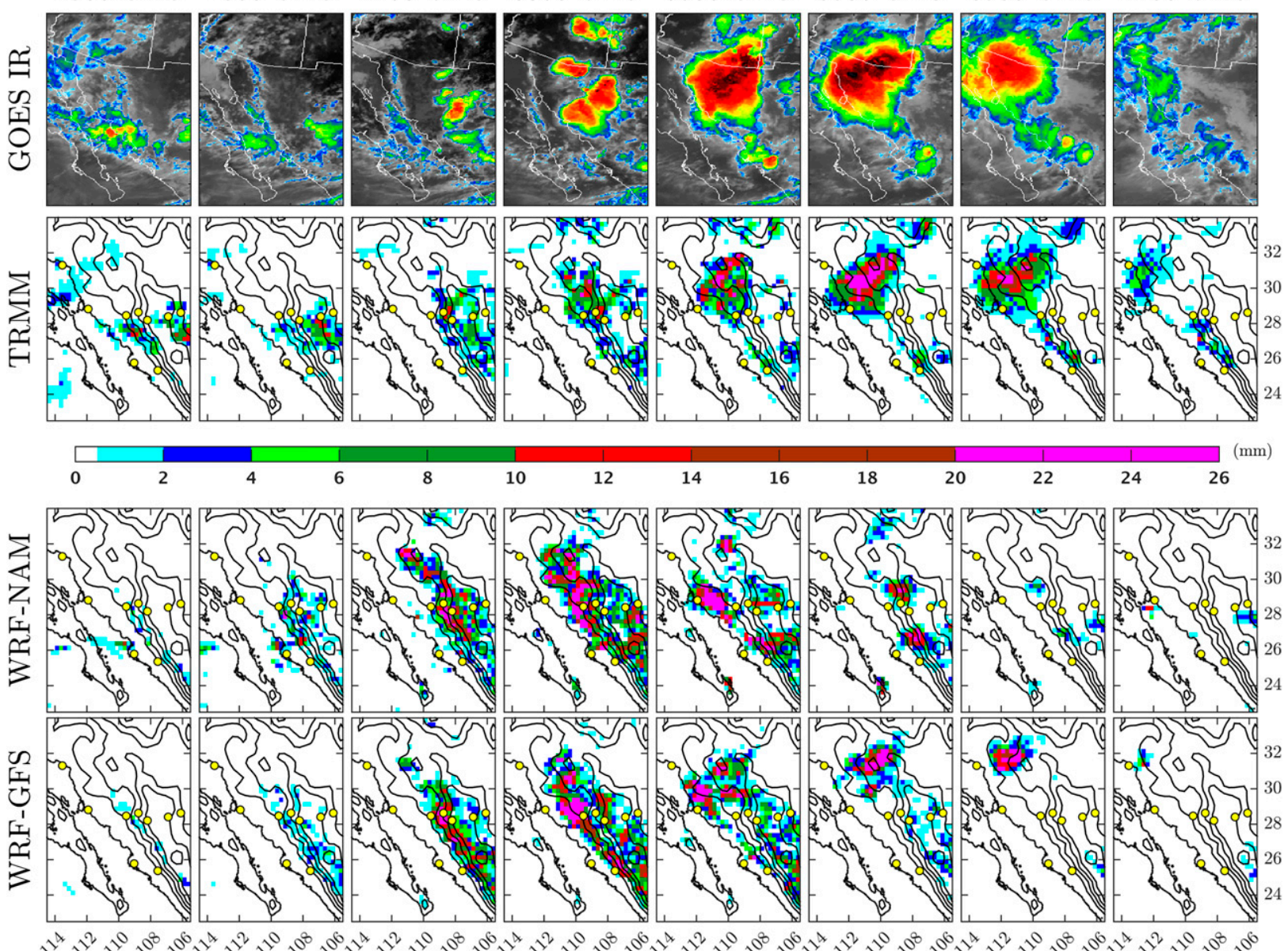

FIG. 14. As in Fig. 13, but for the strongly forced day of 9 Jul 2013.

model-simulated rainfall in northern Sonora to the initial PWV specification at ONVS (Fig. 17, top right) and in the same general location where the MCS is observed to occur via GOES IR imagery (Fig. 13, row 1) and TRMM precipitation (Fig. 13, row 2). Similar patterns of PWV and precipitation sensitivity can also be found at higher-elevation stations along the SMO transect, like MULT and CHIH (not shown), though these stations did not exhibit as strong a sensitivity to forecast PWV and rainfall as ONVS.

These sample results strongly suggest that the WRF Model simulation results would be more sensitive to the initial specification of local PWV west of the SMO crest during the weakly forced days. In other words, as compared to days when an IV is present in this region, a more accurate specification of local moisture conditions during the weakly forced days would have a greater relative impact on the model simulation of organized MCS-type convection. Therefore, we hypothesize that assimilation of GPS-derived PWV may be of greatest value to improve the
WRF precipitation forecasts during the types of days when the obvious synoptic-scale forcing mechanisms to facilitate organized convection are absent. As mentioned in our prior work of Serra et al. (2016), a subsequent study will focus on the assimilating the GPS PWV observations into the WRF-GFS configuration considered here to formally assess this hypothesis.

\section{Conclusions}

Daily WRF-ARW hindcasts of monsoon convection are performed using the forcing data for initial and boundary conditions from the operational GFS and NAM model during the period of Transect 2013. Both WRF-GFS and WRF-NAM hindcasts display a consistent moist bias in the initial specification of PWV when compared to GPS-derived PWV with the WRF-NAM being the wetter of the two. We classify days by their level of synoptic forcing; strongly and weakly forced days are differentiated by the clear presence of an IV. 

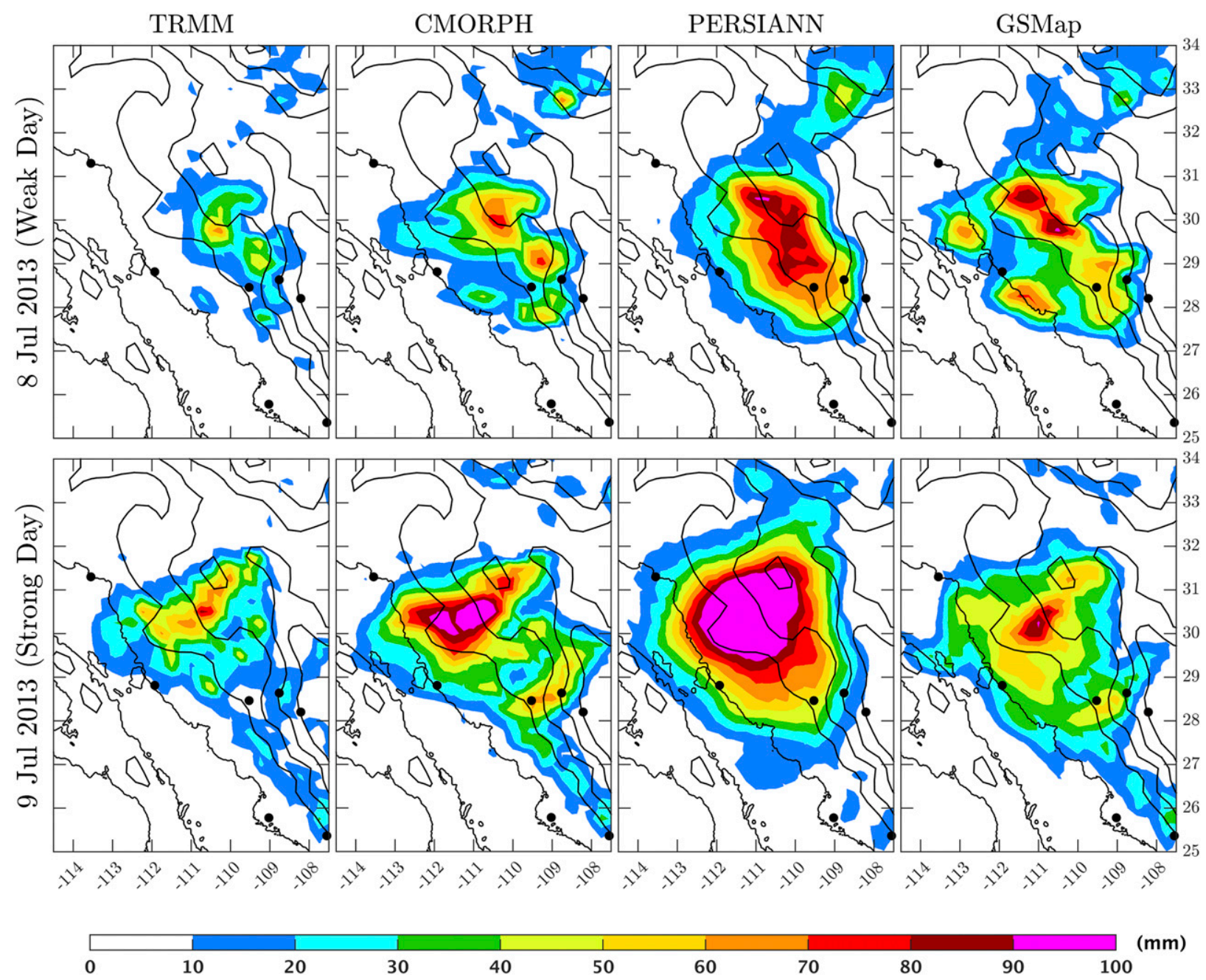

FIG. 15. For the (top) weakly forced (1200 UTC 8 Jul 2013 to 1200 UTC 9 Jul 2013) and (bottom) strongly forced (1200 UTC 9 Jul 2013 to 1200 UTC $10 \mathrm{Jul}$ 2013) day, 24-h rainfall accumulations are shown for the satellite-based precipitation products of TRMM (column 1), CMORPH (column 2), PERSIANN (column 3), and GSMap (column 4). Block dots indicate the locations of a subset of Transect 2013. Terrain is contoured every $500 \mathrm{~m}$ (black lines).

The presence or absence of a gulf surge is not found to alter the WRF hindcasts for MCS development over northwest Mexico in contrast to MCS development in southern Arizona where previous literature indicates a high dependence on antecedent gulf surges. Model forecast precipitation skill is evaluated using the objective CSI, POD, and FAR metrics for the days when appreciable NAM precipitation in observed by TRMM. The strongly forced days initiated over the SMO displayed notably higher precipitation forecast skill than the weakly forced days, especially for areas west of the SMO crest. Therefore, strongly forced days appear to improve the model's ability to deterministically forecast more organized, propagating MCS-type convection that accounts for a greater proportion of the monsoon precipitation west of the SMO crest toward the GoC. The
8-10 July 2013 case study is a clear illustration of this point. During these two days, nearly identical MCSs evolved in the same area in northern Sonora in terms of precipitation amounts and spatial extent of the cloud shield. However, WRF reasonably simulates the MCS only on the day classified as strongly forced, or when an IV is near the initiation region at the highest elevations of the SMO (9-10 July 2013), but not on the weakly forced day (8-9 July 2013) when the IV is located farther east. Relative to the specification of initial modeled PWV at the ONVS Transect 2013 site near the western SMO foothills, we find higher sensitivity to the initial PWV field, 12-h forecast PWV (0000 UTC), and 12-h forecast 12-h rainfall accumulation (0000-1200 UTC) for the weakly forced day than for the strongly forced day. Because ONVS shows higher sensitivity than 


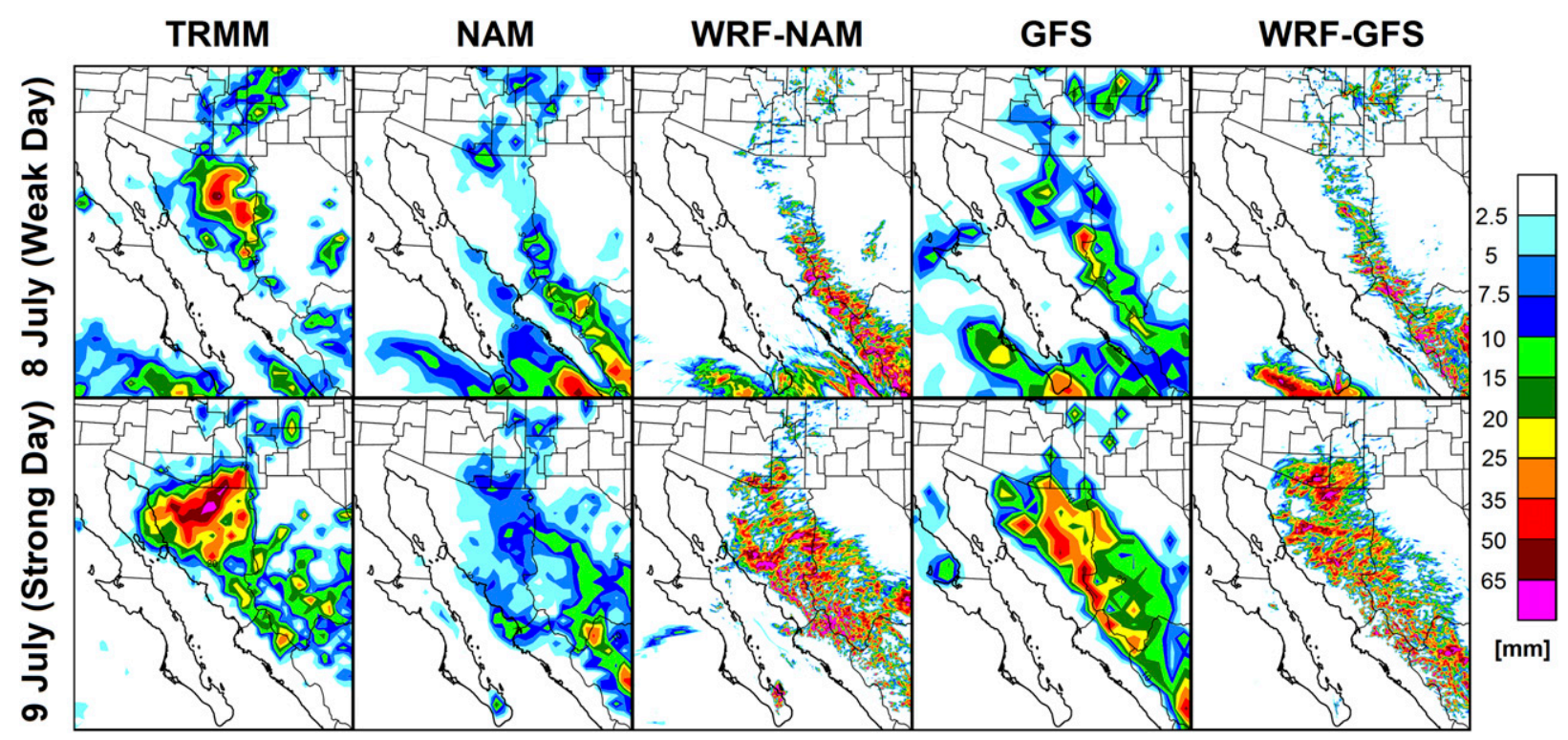

FIG. 16. For the (top) weakly forced (1200 UTC 8 Jul 2013 to 1200 UTC 9 Jul 2013) and (bottom) strongly forced (1200 UTC 9 Jul 2013 to 1200 UTC 10 Jul 2013) day, 24-h rainfall accumulations are shown for TRMM (column 1), NAM (column 2), WRF-NAM (column 3), GFS (column 4), and WRF-GFS (column 5).

higher-elevation sites (e.g., MULT and BASC), we hypothesize that the initial specification of PWV west of the SMO crest is crucial for improved convectivepermitting forecasts especially for MCS-type precipitation. Furthermore, these simulations would potentially benefit the most from the assimilation of GPS-PWV observations on days when synoptic-scale forcing mechanisms (e.g., IVs) that facilitate organized convection are absent. To formally assess this hypothesis, we introduced a subsequent study focusing on assimilating the GPS PWV observations into the WRF configuration in our prior work (Serra et al. 2016).

Acknowledgments. Programa de Apoyo a Proyectos de Investigación e Innovación Tecnológica de la Universidad Nacional Autónoma de México (UNAM PAPIIT) (IA101913 and IA100916) and the Programa de Investigación en Cambio Climático de la Universidad Nacional Autónoma de México (PINCC) provided the majority of funding for the 2013 GPS NAM Transect Experiment. Moker, Castro, Serra, and Arellano and a portion of the Transect 2013 expenses were funded by National Science Foundation Grant AGS-1261226. Additional support was provided by the Consortium for Arizona-Mexico Arid Environments (CAZMEX), through the University of Arizona and the Consejo Nacional de Ciencia y Technología de México. The Transect 2013 data are available from the ResearchWorks archive at the University of Washington at http://hdl.handle.net/1773/37267.

\section{APPENDIX A}

\section{Expanded Analysis Methods}

\section{a. Calculation of $P W V$ in $W R F$}

WRF PWV is calculated as a discrete summation across all model levels for each grid point $(i, j)$ in the d03 domain:

$$
\mathrm{PWV}_{i, j}=\sum_{k=1}^{\text {nlev }}\left(\frac{p_{k}}{R_{d} T_{v k}}\right)\left(\mathrm{QVAPOR}_{k}\right)\left(Z_{k+0.5}-Z_{k-0.5}\right),
$$

where $p_{k}$ is pressure $(\mathrm{Pa}), T_{v k}$ is virtual temperature $(\mathrm{K})$, and QVAPOR ${ }_{k}$ is the water vapor mixing ratio $(\mathrm{kg}$ water vapor $/ \mathrm{kg}$ dry air), and all are associated with the mass point at model level $k$. The geopotential height $(\mathrm{m})$ respective upper and lower bounds on the staggered grid at model level $k$ are $Z_{k+0.5}$ and $Z_{k-0.5}, R_{d}$ is the dry air gas constant, and nlev is 27 , the number of model levels. The variables used in this PWV calculation are first interpolated to the location of the GPS station using an inversedistance weighting of the four closest corresponding model grid points.

\section{b. Forward sensitivity analysis methodology}

Before calculating the sensitivities, we spin up the WRF simulation for $12 \mathrm{~h}$ to get the appropriate variance of state variables in d03. We first add small perturbations on WRF meteorological fields (in the outermost 

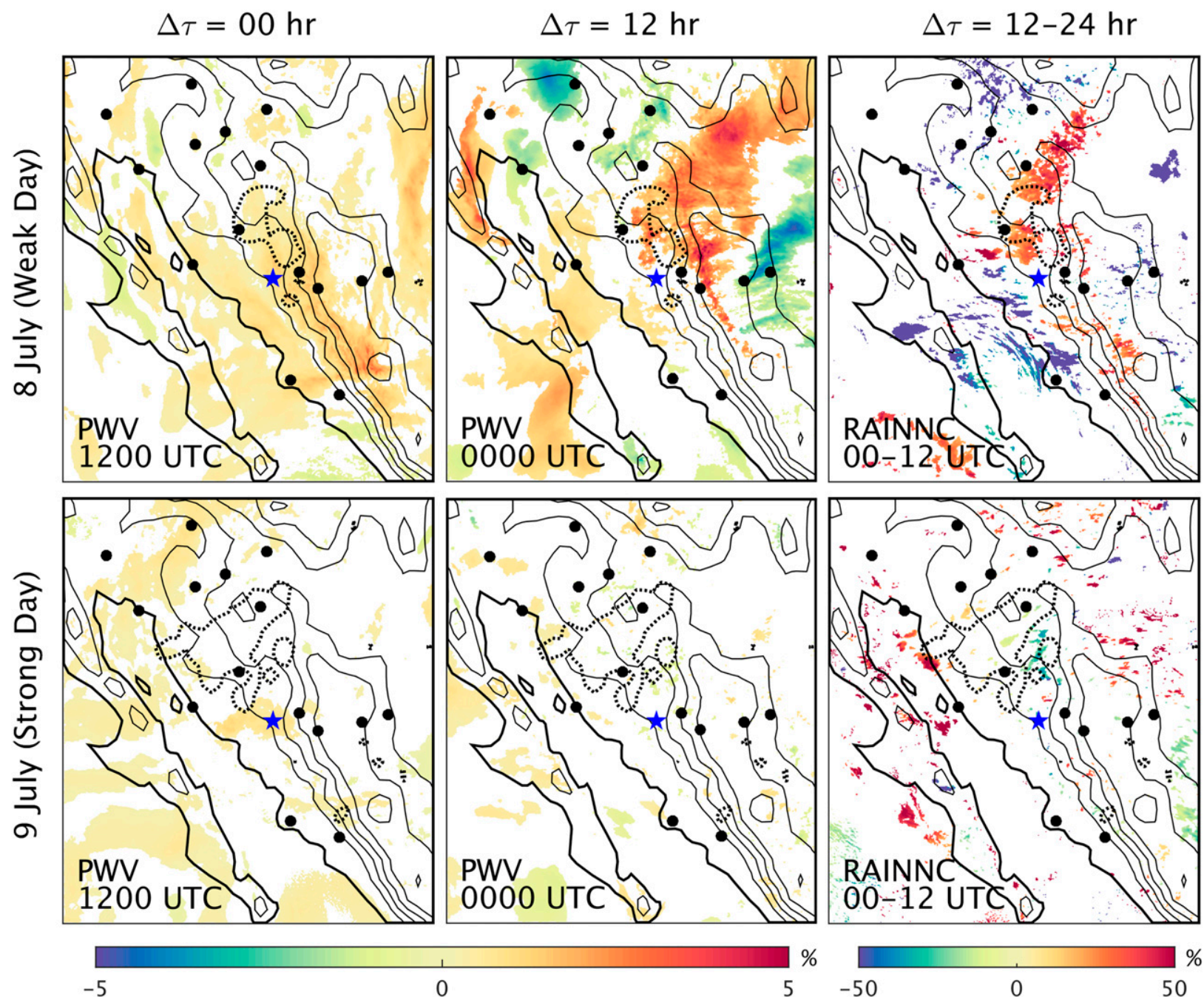

FIG. 17. Relative sensitivity of WRF PWV (columns 1 and 2) and grid-scale rainfall (RAINNC; in domain d03) (column 3 ) at time $t+\Delta \tau$ to changes in the initial condition of PWV at ONVS GPS ground site (marked as a blue star, lon: $109.53^{\circ} \mathrm{W}$, lat: $28.46^{\circ} \mathrm{N}$ ). The sensitivities of ONVS PWV to WRF PWV (\% PWV per \% PWV) at $\Delta \tau=0$ and $\Delta \tau=12$ (columns 1 and 2 ) and ONVS PWV to RAINNC (\% PWV per \% mm) at $\Delta \tau=12$ to 24 (column 3) are presented for both the (top) weakly forced (1200 UTC 8 Jul 2013 to 1200 UTC 9 Jul 2013) and (bottom) strongly forced (1200 UTC 9 Jul 2013 to 1200 UTC $10 \mathrm{Jul} 2013$ ) day. Note: only statistically significant correlations ( $p$ value $<0.05$ ) are shown. The $24-\mathrm{h} 25$-mm TRMM isohyet is plotted by a dotted line. See text for calculation of ensemble-based sensitivities. Terrain is contoured every $500 \mathrm{~m}$ (black lines).

domain: d01) based on the NCEP GFS error covariance (cv3) using the WRF Data Assimilation (WRFDA) tool. Then, we integrate WRF-GFS for $12 \mathrm{~h}$ to propagate these perturbations to the innermost domain (d03). The resulting 40-member ensemble in d03 composes our WRF initial conditions. We sample the model-equivalent GPS PWV for each ensemble member, iens, at a site (refer to section a in this appendix $)$, isite $\left(\mathrm{PWV}_{\mathrm{isit}, t=0 \text {,iens }}^{\bmod }\right)$, using these initial conditions, that is,

$$
\mathrm{PWV}_{\text {isite, } t=0, \text { iens }}^{\text {mod }}=\mathbf{H x}_{\text {iens }}^{\mathrm{mod}}
$$

where $\mathbf{x}_{\text {iens }}^{\text {mod }}$ is the QVAPOR 3D field at $t=0$ for ensemble member iens and $\mathbf{H}$ is the observation operator that maps the model moisture field to site-specific PWV as would be observed from a GPS ground site [see Eq. (A1)]. This operator bilinearly interpolates QVAPOR to a site location and vertically integrates the interpolated profile to get PWV. Thus, we have a 40-element vector, $\mathbf{y}_{\text {isite, } t=0}^{\text {mod }}$, for each GPS site of our study domain.

Starting with the ensemble d03 initial conditions, we generate an ensemble of hourly WRF $2.5-\mathrm{km}$ forecasts with $\Delta \tau$ out to $24 \mathrm{~h}$. For each grid point $(i, j)$ of the model forecast $(t+\Delta \tau)$, we can calculate the relative local sensitivity of WRF Model variable $X_{i, j, t+\Delta \tau}$ to PWV initial conditions at a particular site $\mathrm{PWV}_{\text {isite }, t=0}$ using the statistics from the ensemble forecasts expressed as 


$$
\begin{aligned}
\left(\frac{\Delta X_{i, j, t+\Delta \tau}}{\Delta \mathrm{PWV}_{\text {isite }, t=0}}\right)= & \frac{\operatorname{cov}\left(X_{i, j, t+\Delta \tau}, \mathrm{PWV}_{\text {isite }, t=0}^{\mathrm{mod}}\right)}{\operatorname{var}\left(\mathrm{PWV}_{\text {isite }, t=0}^{\mathrm{mod}}\right)} \\
& \times \frac{\left\langle\mathrm{PWV} V_{\text {isite }, t=0}^{\mathrm{mod}}\right\rangle}{\left\langle X_{i, j, t+\Delta \tau}\right\rangle}
\end{aligned}
$$

Here, $X_{i, j, t+\Delta \tau}$ represents the ensemble WRF forecast of PWV or rainfall at grid point $(i, j)$. In principle $X_{t+\Delta \tau}$ can be any $3 \mathrm{D}$ model forecast variable. The $\langle\cdot\rangle, \operatorname{cov}(\cdot)$, and $\operatorname{var}(\cdot)$ notations represent the expected value (ensemble mean in this case), covariance, and variance across the ensemble, respectively. The PWV at a model grid point is calculated in the same way as Eq. (A2) with $\mathbf{H}$ now corresponding to just the integration of the QVAPOR profile without interpolation. The sensitivity in Eq. (A3) (which is a linear regression estimate) can be interpreted as the local linear sensitivity of the model to changes in PWV initial conditions. This is analogous to the linear sensitivity component of the Kalman gain in an ensemble Kalman filter. A more general concept of ensemble-based sensitivity analysis has been discussed in detail by Torn and Hakim (2008).

\section{APPENDIX B}

\begin{tabular}{|c|c|}
\hline CMORPH & CPC morphing technique \\
\hline CSI & Critical success index \\
\hline ECMWF & $\begin{array}{l}\text { European Centre for Medium-Range } \\
\text { Weather Forecasts }\end{array}$ \\
\hline ERA & ECMWF Re-Analysis \\
\hline ESMF & Earth System Modeling Framework \\
\hline FAR & False-alarm ratio \\
\hline GFS & Global Forecast System \\
\hline GoC & Gulf of California \\
\hline GOES & $\begin{array}{l}\text { Geostationary Operational Environmental } \\
\text { Satellite }\end{array}$ \\
\hline GPM & Global Precipitation Measurement \\
\hline GPS & Global positioning system \\
\hline GSMaP & Global Satellite Mapping of Precipitation \\
\hline HAS & $\begin{array}{l}\text { Department of Hydrology and Atmo- } \\
\text { spheric Sciences }\end{array}$ \\
\hline IV & Inverted trough \\
\hline JAXA & Japan Aerospace Exploration Agency \\
\hline LT & Local time \\
\hline MCS & Mesoscale convective system \\
\hline NAM & $\begin{array}{l}\text { North American Mesoscale Forecast } \\
\text { System }\end{array}$ \\
\hline NAME & North American Monsoon Experiment \\
\hline NARR & North American Regional Reanalysis \\
\hline NASA & $\begin{array}{l}\text { National Aeronautics and Space Adminis- } \\
\text { tration }\end{array}$ \\
\hline
\end{tabular}

\section{Acronyms}

NCL NOAA

NWP

NWS

PERSIANN

POD

PV

PWV

RMSE

SMO

TC

TEW

TMPA

TRMM

TS

UA

UCI

UTC

WRF-ARW

WSR-88D
NCAR Command Language

National Oceanic and Atmospheric Administration

Numerical weather prediction

National Weather Service

Precipitation Estimation from Remotely Sensed Information Using Artificial Neural Networks

Probability of detection

Potential vorticity

Precipitable water vapor

Root-mean-square error

Sierra Madre Occidental

Tropical cyclone

Tropical easterly wave

TRMM Multisatellite Precipitation Algorithm

$$
\begin{aligned}
& \text { Tropical Rainfall Measuring Mission } \\
& \text { Tropical storm } \\
& \text { University of Arizona } \\
& \text { University of California, Irvine } \\
& \text { Universal coordinated time } \\
& \text { Advanced Research version of the Weather } \\
& \text { Research and Forecasting Model } \\
& \text { Weather Surveillance Radar-1988 Doppler }
\end{aligned}
$$

\section{REFERENCES}

Adams, D. K., and A. C. Comrie, 1997: The North American monsoon. Bull. Amer. Meteor. Soc., 78, 2197-2214, https:// doi.org/10.1175/1520-0477(1997)078<2197:TNAM >2.0.CO;2.

— , and E. P. Souza, 2009: CAPE and convective events in the Southwest during the North American monsoon. Mon. Wea. Rev., 137, 83-98, https://doi.org/10.1175/2008MWR2502.1.

— , and Coauthors, 2011: A dense GNSS meteorological network for observing deep convection in the Amazon. Atmos. Sci. Lett., 12, 207-212, https://doi.org/10.1002/asl.312.

— S. I. Gutman, K. L. Holub, and D. S. Pereira, 2013: GNSS observations of deep convective time scales in the Amazon. Geophys. Res. Lett., 40, 2818-2823, https://doi.org/10.1002/grl.50573.

, C. Minjarez, Y. Serra, A. Quintanar, L. Alatorre, A. Granados, E. Vázquez, and J. Braun, 2014: Mexican GPS tracks convection from North American monsoon. Eos, Trans. Amer. Geophys. Union, 95, 61-68, https://doi.org/10.1002/ 2014EO070001.

- , and Coauthors, 2015: The Amazon dense GNSS meteorological network: A new approach for examining water vapor and deep convection interactions in the tropics. Bull. Amer. Meteor. Soc., 96, 2151-2165, https://doi.org/10.1175/BAMS-D-13-00171.1.

Aonashi, K., and Coauthors, 2009: GSMaP passive microwave precipitation retrieval algorithm: Algorithm description and validation. J. Meteor. Soc. Japan, 87A, 119-136, https:// doi.org/10.2151/jmsj.87A.119.

Becker, E. J., and E. H. Berbery, 2008: The diurnal cycle of precipitation over the North American monsoon region during 
the NAME 2004 field campaign. J. Climate, 21, 771-787, https://doi.org/10.1175/2007JCLI1642.1.

Bevis, M., S. Businger, T. A. Herring, C. Rocken, R. A. Anthes, and R. H. Ware, 1992: GPS meteorology: Remote sensing of atmospheric water vapor using the global positioning system. J. Geophys. Res., 97, 15787-15801, https://doi.org/10.1029/ 92JD01517.

Bieda, S. W., III, C. L. Castro, S. L. Mullen, A. C. Comrie, and E. Pytlak, 2009: The relationship of transient upper-level troughs to variability of the North American monsoon system. J. Climate, 22, 4213-4227, https://doi.org/10.1175/2009JCLI2487.1.

Brenner, I. S., 1974: A surge of maritime tropical air-Gulf of California to the southwestern United States. Mon. Wea. Rev., 102, 375-389, https://doi.org/10.1175/1520-0493(1974)102<0375: ASOMTA $>2.0 . \mathrm{CO} ; 2$

Carleton, A. M., 1986: Synoptic-dynamic character of "bursts" and "breaks" in the south-west U.S. summer precipitation singularity. J. Climatol., 6, 605-623, https://doi.org/10.1002/ joc.3370060604.

, D. A. Carpenter, and P. J. Weser, 1990: Mechanisms of interannual variability of the southwest United States summer rainfall maximum. J. Climate, 3, 999-1015, https://doi.org/ 10.1175/1520-0442(1990)003<0999:MOIVOT>2.0.CO;2.

Castro, C. L., R. A. Pielke Sr., and J. O. Adegoke, 2007: Investigation of the summer climate of the contiguous United States and Mexico using the Regional Atmospheric Modeling System (RAMS). Part I: Model climatology (1950-2002). J. Climate, 20, 3844-3865, https://doi.org/10.1175/JCLI4211.1.

Chen, S., and Coauthors, 2015: Intercomparison of precipitation estimates from WSR-88D radar and TRMM measurement over continental United States. IEEE Trans. Geosci. Remote Sens., 53, 4444-4456, https://doi.org/ 10.1109/TGRS.2015.2399307.

Chou, M.-D., and M. J. Suarez, 1999: A solar radiation parameterization for atmospheric studies. Tech. Memo. NASA/TM1999-104606, Vol. 15, 38 pp., http://gmao.gsfc.nasa.gov/pubs/ docs/Chou136.pdf.

- _ - X.-Z. Liang, and M. M.-H. Yan, 2001: A thermal infrared radiation parameterization for atmospheric studies. NASA/TM-2001-104606, Vol. 19, 54 pp., https://ntrs.nasa.gov/ archive/nasa/casi.ntrs.nasa.gov/20010072848.pdf.

Collier, J. C., and G. J. Zhang, 2007: Effects of increased horizontal resolution on simulation of the North American monsoon in the NCAR CAM3: An evaluation based on surface, satellite, and reanalysis data. J. Climate, 20, 1843-1861, https://doi.org/ 10.1175/JCLI4099.1.

Damiani, R., and Coauthors, 2008: The Cumulus, Photogrammetric, In Situ, and Doppler Observations Experiment of 2006. Bull. Amer. Meteor. Soc., 89, 57-73, https://doi.org/10.1175/ BAMS-89-1-57.

Dee, D. P., and Coauthors, 2011: The ERA-Interim reanalysis: Configuration and performance of the data assimilation system. Quart. J. Roy. Meteor. Soc., 137, 553-597, https://doi.org/10.1002/qj.828.

Donaldson, R. J., R. M. Dyer, and M. J. Krauss, 1975: An objective evaluator of techniques for predicting severe weather events. Preprints, Ninth Conf. on Severe Local Storms, Norman, OK, Amer. Meteor. Soc., 321-326.

Douglas, A. V., and P. J. Englehart, 2007: A climatological perspective of transient synoptic features during NAME 2004. J. Climate, 20, 1947-1954, https://doi.org/10.1175/JCLI4095.1.

Douglas, M. W., and J. C. Leal, 2003: Summertime surges over the Gulf of California: Aspects of their climatology, mean structure, and evolution from radiosonde, NCEP reanalysis, and rainfall data. Wea. Forecasting, 18, 55-74, https://doi.org/ 10.1175/1520-0434(2003)018<0055:SSOTGO>2.0.CO;2.

_ R. A. Maddox, K. Howard, and S. Reyes, 1993: The Mexican monsoon. J. Climate, 6, 1665-1677, https://doi.org/10.1175/ 1520-0442(1993)006<1665:TMM > 2.0.CO;2.

Finch, Z. O., and R. H. Johnson, 2010: Observational analysis of an upper-level inverted trough during the North American Monsoon Experiment. Mon. Wea. Rev., 138, 3540-3555, https://doi.org/10.1175/2010MWR3369.1.

Fuller, R. D., and D. J. Stensrud, 2000: The relationship between tropical easterly waves and surges over the Gulf of California during the North American monsoon. Mon. Wea. Rev., 128, 2983-2989, https://doi.org/10.1175/1520-0493(2000)128<2983: TRBTEW $>2.0 . \mathrm{CO} ; 2$.

Gochis, D. J., C. J. Watts, J. Garatuza-Payan, and J. CesarRodriguez, 2007: Spatial and temporal patterns of precipitation intensity as observed by the NAME Event Rain Gauge Network from 2002 to 2004. J. Climate, 20, 1734-1750, https://doi.org/10.1175/JCLI4092.1.

Griffiths, P. G., C. S. Magirl, R. H. Webb, E. Pytlak, P. A. Troch, and S. W. Lyon, 2009: Spatial distribution and frequency of precipitation during an extreme event: July 2006 mesoscale convective complexes and floods in southeastern Arizona. Water Resour. Res., 45, W07419, https://doi.org/10.1029/2008WR007380.

Gutzler, D. S., and Coauthors, 2009: Simulations of the 2004 North American monsoon: NAMAP2. J. Climate, 22, 6716-6740, https://doi.org/10.1175/2009JCLI3138.1.

Hales, J. E., Jr., 1972: Surges of maritime tropical air northward over Gulf of California. Mon. Wea. Rev., 100, 298-306, https:// doi.org/10.1175/1520-0493(1972)100<0298:SOMTAN>2.3.CO;2.

Higgins, W., and W. Shi, 2005: Relationships between Gulf of California moisture surges and tropical cyclones in the eastern Pacific basin. J. Climate, 18, 4601-4620, https://doi.org/ 10.1175/JCLI3551.1.

, and D. Gochis, 2007: Synthesis of results from the North American Monsoon Experiment (NAME) process study. J. Climate, 20, 1601-1607, https://doi.org/10.1175/JCLI4081.1.

, W. Shi, and C. Hain, 2004: Relationships between Gulf of California moisture surges and precipitation in the southwestern United States. J. Climate, 17, 2983-2997, https://doi.org/10.1175/ 1520-0442(2004)017<2983:RBGOCM >2.0.CO;2.

— , and Coauthors, 2006: The NAME 2004 field campaign and modeling strategy. Bull. Amer. Meteor. Soc., 87, 79-94, https:// doi.org/10.1175/BAMS-87-1-79.

Hodges, K. I., 1994: A general method for tracking analysis and its application to meteorological data. Mon. Wea. Rev., 122, 2573-2586, https://doi.org/10.1175/1520-0493(1994)122<2573: AGMFTA $>2.0 . \mathrm{CO} ; 2$.

- 1995: Feature tracking on the unit sphere. Mon. Wea. Rev., 123, 3458-3465, https://doi.org/10.1175/1520-0493(1995)123<3458: FTOTUS $>2.0 . \mathrm{CO} ; 2$.

Hong, S.-Y., and J.-O. J. Lim, 2006: The WRF single-moment 6-class microphysics scheme (WSM6). J. Korean Meteor. Soc., 42, 129-151.

__ Y. Noh, and J. Dudhia, 2006: A new vertical diffusion package with an explicit treatment of entrainment processes. Mon. Wea. Rev., 134, 2318-2341, https://doi.org/10.1175/MWR3199.1.

Huffman, G. J., and Coauthors, 2007: The TRMM Multisatellite Precipitation Analysis (TMPA): Quasi-global, multiyear, combined-sensor precipitation estimates at fine scales. J. Hydrometeor., 8, 38-55, https://doi.org/10.1175/JHM560.1.

Iacono, M. J., J. S. Delamere, E. J. Mlawer, M. W. Shephard, S. A. Clough, and W. D. Collins, 2008: Radiative forcing by long-lived 
greenhouse gases: Calculations with the AER radiative transfer models. J. Geophys. Res., 113, D13103, https://doi.org/10.1029/ 2008JD009944.

Johnson, R. H., P. E. Ciesielski, B. D. McNoldy, P. J. Rogers, and R. K. Taft, 2007: Multiscale variability of the flow during the North American Monsoon Experiment. J. Climate, 20, 16281648, https://doi.org/10.1175/JCLI4087.1.

Joyce, R. J., J. E. Janowiak, P. A. Arkin, and P. Xie, 2004: CMORPH: A method that produces global precipitation estimates from passive microwave and infrared data at high spatial and temporal resolution. J. Hydrometeor., 5, 487-503, https:// doi.org/10.1175/1525-7541(2004)005<0487:CAMTPG >2.0.CO;2.

Kain, J. S., 2004: The Kain-Fritsch convective parameterization: An update. J. Appl. Meteor., 43, 170-181, https://doi.org/ 10.1175/1520-0450(2004)043<0170:TKCPAU>2.0.CO;2.

Kubota, T., and Coauthors, 2007: Global precipitation map using satellite-borne microwave radiometers by the GSMaP project: Production and validation. IEEE Trans. Geosci. Remote Sens. 45, 2259-2275, https://doi.org/10.1109/TGRS.2007.895337.

Kursinski, E. R., D. K. Adams, and M. Leuthold, 2008a: GPS observations of precipitable water and implications for the predictability of precipitation during the North American monsoon. CLIVAR Exchanges, No. 45, International CLIVAR Project Office, Southampton, United Kingdom, 14, 19-21.

_ and Coauthors, 2008b: Water vapor and surface observations in northwestern Mexico during the 2004 NAME enhanced observing period. Geophys. Res. Lett., 35, L03815, https:// doi.org/10.1029/2007GL031404.

Lahmers, T. M., C. L. Castro, D. K. Adams, Y. L. Serra, J. J. Brost, and T. M. Luong, 2016: Long-term changes in the climatology of transient inverted troughs over the North American monsoon region and their effects on precipitation. J. Climate, 29, 6037-6064, https://doi.org/10.1175/JCLI-D-15-0726.1.

Lang, T. J., D. A. Ahijevych, S. W. Nesbitt, R. E. Carbone, S. A. Rutledge, and R. Cifelli, 2007: Radar-observed characteristics of precipitating systems during NAME 2004. J. Climate, 20, 1713-1733, https://doi.org/10.1175/JCLI4082.1.

Lee, M.-I., and Coauthors, 2007: Sensitivity to horizontal resolution in the AGCM simulations of warm season diurnal cycle of precipitation over the United States and northern Mexico. J. Climate, 20, 1862-1881, https://doi.org/10.1175/ JCLI4090.1.

Li, J., S. Sorooshian, W. Higgins, X. Gao, B. Imam, and K. Hsu, 2008: Influence of spatial resolution on diurnal variability during the North American monsoon. J. Climate, 21, 39673988, https://doi.org/10.1175/2008JCLI2022.1.

Livezey, R. E., and W. Y. Chen, 1983: Statistical significance and its determination by Monte Carlo techniques. Mon. Wea. Rev. 111, 46-59, https://doi.org/10.1175/1520-0493(1983)111<0046: SFSAID $>2.0 . \mathrm{CO} ; 2$

Luong, T. M., C. L. Castro, H.-I. Chang, T. Lahmers, D. K. Adams, and C. A. Ochoa-Moya, 2017: The more extreme nature of North American monsoon precipitation in the southwestern United States as revealed by a historical climatology of simulated severe weather events. J. Appl. Meteor. Climatol., 56, 2509-2529, https://doi.org/10.1175/JAMC-D-16-0358.1.

Magirl, C. S., and Coauthors, 2007: Impact of recent extreme Arizona storms. Eos, Trans. Amer. Geophys. Union, 88, $191-$ 193, https://doi.org/10.1029/2007EO170003.

Mason, I., 1989: Dependence of the critical success index on sample climate and threshold probability. Aust. Meteor. Mag., 37, 75-81.

McCollum, D. M., R. A. Maddox, and K. W. Howard, 1995: Case study of a severe mesoscale convective system in central
Arizona. Wea. Forecasting, 10, 643-665, https://doi.org/ 10.1175/1520-0434(1995)010<0643:CSOASM>2.0.CO;2.

Mesinger, F., and Coauthors, 2006: North American Regional Reanalysis. Bull. Amer. Meteor. Soc., 87, 343-360, https:// doi.org/10.1175/BAMS-87-3-343.

Moncrieff, M. W., and M. J. Miller, 1976: The dynamics and simulation of tropical cumulonimbus and squall lines. Quart. J. Roy. Meteor. Soc., 102, 373-394, https://doi.org/10.1002/qj.49710243208.

Moore, A., and Coauthors, 2015: National Weather Service forecasters use GPS precipitable water vapor for enhanced situational awareness during the Southern California summer monsoon. Bull. Amer. Meteor. Soc., 96, 1867-1877, https:// doi.org/10.1175/BAMS-D-14-00095.1.

Nesbitt, S. W., D. J. Gochis, and T. J. Lang, 2008: The diurnal cycle of clouds and precipitation along the Sierra Madre Occidental observed during NAME-2004: Implications for warm season precipitation estimation in complex terrain. J. Hydrometeor., 9, 728-743, https://doi.org/10.1175/2008JHM939.1.

Newman, A., and R. H. Johnson, 2012: Mechanisms for precipitation enhancement in a North American monsoon uppertropospheric trough. J. Atmos. Sci., 69, 1775-1792, https:// doi.org/10.1175/JAS-D-11-0223.1.

Okamoto, K. I., T. Ushio, T. Iguchi, N. Takahashi, and K. Iwanami, 2005: The Global Satellite Mapping of Precipitation (GSMaP) project. Proc. IEEE 2005 Int. Geoscience and Remote Sensing Symp., Vol. 5, Seoul, South Korea, Institute of Electrical and Electronics Engineers, 3414-3416.

Pytlak, E., M. Goering, and A. Bennett, 2005: Upper tropospheric troughs and their interaction with the North American monsoon. 19th Conf. on Hydrology, San Diego, CA, Amer. Meteor. Soc., P2.3, https://ams.confex.com/ams/pdfpapers/85393.pdf.

Raymond, D., and M. Wilkening, 1980: Mountain-induced convection under fair weather conditions. J. Atmos. Sci., 37, 2693-2706, https:// doi.org/10.1175/1520-0469(1980)037<2693:MICUFW>2.0.CO;2.

Rogers, P. J., and R. H. Johnson, 2007: Analysis of the 13-14 July gulf surge event during the 2004 North American Monsoon Experiment. Mon. Wea. Rev., 135, 3098-3117, https://doi.org/ 10.1175/MWR3450.1.

Rowe, A. K., S. A. Rutledge, and T. J. Lang, 2012: Investigation of microphysical processes occurring in organized convection during NAME. Mon. Wea. Rev., 140, 2168-2187, https:// doi.org/10.1175/MWR-D-11-00124.1.

Schaefer, J. T., 1990: The critical success index as an indicator of warning skill. Wea. Forecasting, 5, 570-575, https://doi.org/ 10.1175/1520-0434(1990)005<0570:TCSIAA > 2.0.CO;2.

Seastrand, S., Y. L. Serra, C. L. Castro, and E. Ritchie, 2015: The dominant synoptic-scale modes of North American monsoon precipitation. Int. J. Climatol., 35, 2019-2032, https://doi.org/ $10.1002 /$ joc. 4104 .

Serra, Y. L., G. N. Kiladis, and K. I. Hodges, 2010: Tracking and mean structure of easterly waves over the Intra-Americas Sea.J. Climate, 23, 4823-4840, https://doi.org/10.1175/2010JCLI3223.1. and Coauthors, 2016: The North American Monsoon GPS Transect Experiment 2013. Bull. Amer. Meteor. Soc., 97, 21032115, https://doi.org/10.1175/BAMS-D-14-00250.1.

Skamarock, W. C., J. B. Klemp, J. Dudhia, D. O. Gill, D. M. Barker, W. Wang, and J. G. Powers, 2005: A description of the Advanced Research WRF version 2. NCAR Tech. Note NCAR/TN-468+STR, 88 pp., http://dx.doi.org/10.5065/ D6DZ069T.

, and Coauthors, 2008: A description of the Advanced Research WRF version 3. NCAR Tech. Note NCAR/TN-475+STR, 113 pp., http://dx.doi.org/10.5065/D68S4MVH. 
Sorooshian, S., K.-L. Hsu, X. Gao, H. V. Gupta, B. Imam, and D. Braithwaite, 2000: Evaluation of PERSIANN system satellitebased estimates of tropical rainfall. Bull. Amer. Meteor. Soc., 81, 2035-2046, https://doi.org/10.1175/1520-0477(2000)081<2035: EOPSSE $>2.3 . \mathrm{CO} ; 2$.

Stillman, S., X. Zeng, and M. G. Bosilovich, 2016: Evaluation of 22 precipitation and 23 soil moisture products over a semiarid area in southeastern Arizona. J. Hydrometeor., 17, 211-230, https://doi.org/10.1175/JHM-D-15-0007.1.

Tewari, M., and Coauthors, 2004: Implementation and verification of the unified NOAH land surface model in the WRF model. 20th Conf. on Weather Analysis and Forecasting/16th Conf. on Numerical Weather Prediction, Seattle, WA, Amer. Meteor. Soc., 14.2A, https://ams.confex.com/ams/pdfpapers/ 69061.pdf.

Thorncroft, C., and K. Hodges, 2001: African easterly wave variability and its relationship to Atlantic tropical cyclone activity. J. Climate, 14, 1166-1179, https://doi.org/10.1175/15200442(2001)014<1166:AEWVAI>2.0.CO;2.

Tian, Y., C. D. Peters-Lidard, R. F. Adler, T. Kubota, and T. Ushio, 2010: Evaluation of GSMaP precipitation estimates over the contiguous United States. J. Hydrometeor., 11, 566-574, https://doi.org/10.1175/2009JHM1190.1.

Torn, R. D., and G. J. Hakim, 2008: Ensemble-based sensitivity analysis. Mon. Wea. Rev., 136, 663-677, https://doi.org/ 10.1175/2007MWR2132.1.

Ushio, T., and Coauthors, 2009: A Kalman filter approach to the Global Satellite Mapping of Precipitation (GSMaP) from combined passive microwave and infrared radiometric data. J. Meteor Soc. Japan, 87A, 137-151, https://doi.org/10.2151/jmsj.87A.137.

Wilks, D. S., 1995: Statistical Methods in the Atmospheric Sciences: An Introduction. Academic Press, $467 \mathrm{pp}$.

Wood, K. M., and E. A. Ritchie, 2013: An updated climatology of tropical cyclone impacts on the southwestern United States. Mon. Wea. Rev., 141, 4322-4336, https://doi.org/10.1175/ MWR-D-13-00078.1.

Zehnder, J. A., 2004: Dynamic mechanisms of the gulf surge. J. Geophys. Res., 109, D10107, https://doi.org/10.1029/2004JD004616.

Zuidema, P., C. Fairall, L. M. Hartten, J. E. Hare, and D. Wolfe, 2007: On the air-sea interaction at the mouth of the Gulf of California. J. Climate, 20, 1649-1661, https://doi.org/10.1175/ JCLI4089.1. 